This item was submitted to Loughborough's Research Repository by the author.

Items in Figshare are protected by copyright, with all rights reserved, unless otherwise indicated.

\title{
Does collaboration pay in agricultural supply chain? An empirical approach
}

PLEASE CITE THE PUBLISHED VERSION

https://doi.org/10.1080/00207543.2018.1440654

PUBLISHER

(C) Taylor \& Francis

VERSION

AM (Accepted Manuscript)

PUBLISHER STATEMENT

This work is made available according to the conditions of the Creative Commons Attribution-NonCommercialNoDerivatives 4.0 International (CC BY-NC-ND 4.0) licence. Full details of this licence are available at: https://creativecommons.org/licenses/by-nc-nd/4.0/

\section{LICENCE}

CC BY-NC-ND 4.0

\section{REPOSITORY RECORD}

Despoudi, Stella, Grammatoula Papaioannou, George Saridakis, and Samir Dani. 2019. "Does Collaboration Pay in Agricultural Supply Chain? an Empirical Approach". figshare. https://hdl.handle.net/2134/28368. 


\title{
Does Collaboration Pay in Agricultural Supply Chain? An Empirical Approach
}

\author{
Stella Despoudi \\ Coventry University, Coventry Business School \\ S.Despoudi@coventry.ac.uk \\ Grammatoula Papaioannou (corresponding author) \\ Loughborough University, School of Business and Economics \\ G.Papaioannou@1boro.ac.uk \\ George Saridakis \\ University of Kent, Kent Business School \\ G.Saridakis@kent.ac.uk \\ Samir Dani \\ University of Huddersfield, Huddersfield Business School \\ S.S.Dani@hud.ac.uk
}

\begin{abstract}
This paper examines the effect of different types of collaboration on the level of Postharvest Food Losses (PHFL) and the proportion of low-quality peaches produced using a unique dataset of Greek peach producers. Quantile regression techniques are adopted to estimate the effects at different points of the conditional distribution of our variables of interest. The findings of this study suggest that high levels of collaboration between producers and cooperatives are associated with both low levels of PHFL and a low proportion of low-quality peaches. We also find that specific types of collaboration, such as 'goal congruence', can play a significant role in reducing PHFL and improving the quality of peach production at the extremes of the distribution. Important policy implications regarding collaborative practices and systems that can be implemented to reduce PHFL and boost a producer's performance together with sustainability credentials are drawn from this study.
\end{abstract}

Keywords: Agricultural Supply Chain, Postharvest Food Loss, Supply Chain Collaboration, Performance Measures, Empirical Study 


\section{Introduction}

The Agricultural Supply Chain (ASC) is increasingly subjected to sustainability standards as well as market requirements related to quality, consistency, and safety (Borodin et al., 2014; Golini et al., 2017). The perishable nature of the produce and the high fluctuations in demand and prices are additional challenges in managing the fresh produce ASC compared to other supply chains (Shukla and Jharkharia, 2013). The focus on product quality and sustainability simultaneously creates further complexity in managing the ASC (Van der Vorst et al., 2009). However, sustainability standards and performance requirements can help in reducing several risks for supply chain entities such as low quality, delivery failure, demand, and climate extremes risks (Diabat et al., 2011, Nakandala et al., 2017). A major challenge in ASCs is food waste and primarily Postharvest Food Losses (PHFL) (Halloran et al., 2014). PHFL refers to reductions in edible food mass throughout the part of the supply chain that specifically leads to edible food for human consumption and includes all the edible food that was lost unintentionally (FAO, 2013a, 2013b). Food is lost or wasted throughout the supply chain from initial agricultural production down to final household consumption (Gustavsson et al., 2011). It has been estimated that between $25 \%$ and $50 \%$ of the food produced is lost or wasted along the ASC and does not reach consumers, depending on its position in the supply chain (FAO, 2010; FAO, 2013a). The Business Continuity Institute (2013) states that over half of the disruptions in the supply chain or about $58 \%$ happens at the first link or tier, that is, the producers. Developed countries are expected to increase their agricultural production in order to respond to a high population increase by 2050 (Alexandratos and Bruinsma, 2012). Reducing PHFL can increase grain supply, food availability and food security without wasting other resources such as land, labour, water and inputs (The World Bank, 2011; Kummu et al., 2012). The EU has set a target of reducing PHFL levels within the European food sector by half until 2030 (European Union, 2016).

Mena et al. (2011) suggest that better and closer strategic collaboration between suppliers and retailers can help to deal with the majority of root causes of PHFL. For example, creating a competitive advantage through learning alliances resources, sharing information and knowledge, networks and making joint strategic and trading decisions can result in reducing PHFL. Moreover, collaboration can foster and extend innovation, entrepreneurship and improve a firm's overall growth 
prospects and position in the marketplace (Fink et al., 2008; Spence et al., 2008; Cao et al., 2010; Golonka, 2015; De Silva et al., 2017). Barratt (2004) stated that in order to define collaboration it needs to be applied in a specific context. Specific contextual factors can influence the nature of collaboration in supply chains (Danese, 2011). The nature and types of collaboration may have in the ASC can influence negatively or positively its special characteristics such as perishability of the products, quality standards, and the business environment (Fischer et al., 2010; Tsolakis et al., 2014).

ASC entities have tried to engage in collaborative relationships in an effort to increase their performance and competitive advantages (Christopher and Holweg, 2011). In particular, producers are the start of the food supply chain and historically they have been practitioners of collaboration, whether formal or informal. Informal collaboration generally occurs during situations, such as harvesting, when the work load is heavy. Such collaborations are usually with family and neighbors and are of great importance for the small scale family operated farms (Cialdella et al., 2009). On the other hand, cooperatives are the avenues of formal collaboration and they facilitate greater efficiencies in the production, distribution and marketing aspects. It has been reported that collaboration between agricultural cooperatives and their members in EU are becoming more heterogonous due to the EU market deregulation (Hovelaque et al., 2009) and there is a need for cooperatives to identify new ways of addressing member disengagement and heterogeneity (EEFP, 2014). Additionally, the review of literature on the impact of collaboration on business performance from the firms, manufacturers and retailers' perspective provide a mixed evidence to support the notion that collaboration can reduce PHFL (see, for example, Cao et al., 2010; Kenneth et al., 2012). This undermines its role in ASC policy agenda. Hence, the possible relationship between collaboration and business performance (i.e. PHFL) needs to be further examined within the ASC context.

The literature on PHFL has shown that although collaborative efforts have emerged, due to the special characteristics of the ASC, PHFL levels are considerably high (Kummu et al., 2012). This paper contributes to the existing literature (Hyvönen and Tuominen, 2007; William and Filippini, 2009; Singh and Power, 2009; Stank et al., 2001) by examining the effect of collaboration between 
the producers and their buyers i.e. agricultural cooperatives on PHFL in the fresh produce ASC. ${ }^{1}$ This research focuses on B2B relationship and does not delve into food loss at the retailer or home. Food loss at the retailer and home of the consumer is researched widely from an individual entity perspective (retailer operations, or consumer food use). In particular the focus is on the upstream ASC given the fact that the majority of the PHFL happens from the producers to their buyer stage and research regarding PHFL from the producers' perspective (Parfitt et al., 2010, FAO, 2012; FAO, 2013a; Business Continuity Institute, 2013) may provide significant insights in this area.

This research is conducted in Greece, a country with the largest agricultural labour forces within the EU-28, having 723,010 agricultural holdings, and the fifth largest producer of fresh agricultural products in Europe (Eurostat, 2016). Fresh agricultural products are the main exporting agricultural products of Greece and the majority of fresh produce in Greece is sold through the agricultural cooperatives (Manos and Manikas, 2010). Also, fruit and vegetables, along with olive oil and wheat constitute a large part of the national agricultural economy in Greece- expressed in terms of employment, production area, volume and value - and the most important fruits are grapes, peaches, oranges, apples and watermelons (Kaditi, 2010).

The fresh peach agricultural product is selected as a representative product of the Greek ASC. This is because peaches are highly perishable products and they may have high levels of PHFL (Parfitt et al., 2010). ${ }^{2}$ PHFL is measured both in tonnes and as a proportion of total production and quantile regression techniques are used to examine the entire conditional distribution of our dependent variable (Koenker and Hallock, 2001; Koenker and Bassett, 1978). The objective of this study is to examine the relationship between collaboration in the fresh produce ASC and PHFL. To do so, seven types of collaboration in ASC (information sharing, goal congruence, decision synchronisation, incentive alignment, resource sharing, collaborative communication and joint knowledge creation) and their impact on PHFL in tonnes and as proportion of the total production are identified. The results suggest that high levels of collaboration between producers and cooperatives are negatively

\footnotetext{
${ }^{1}$ The potential association between collaboration and PHFL in the ASC was preliminarily discussed within the $\mathrm{PhD}$ thesis of one of the co-authors (Despoudi, 2016).

${ }^{2}$ Notably, in 2012, Greece was the fourth largest producer of peaches and nectarines worldwide, after China, Italy, and United States of America (FAO, 2012).
} 
associated with PHFL. More importantly, this paper provides new and possibly more refined evidence of the association between collaboration and PHFL by considering different types of collaboration and investigating the relationship at a range of points of the conditional PHFL distribution.

The paper is organized as follows: section 2 presents the review of literature and derives the hypotheses. Section 3 discusses the research methodology and data used. Section 4 presents the statistical model used in this paper. In section 5 the results are discussed together with potential policy implications. Section 6 draws conclusions and directions for future research.

\section{Literature review}

\subsection{Definitions}

The ASC encompasses the activities from production to distribution that bring agricultural or horticultural products from the farm to the table (Aramyan and Van Gogh, 2014). The ASC comprises organizations responsible for production (producers), distribution, processing, and marketing of agricultural products to the final consumers. There are two different types of ASCs: i) supply chain of fresh agricultural products and ii) supply chain for non-perishable agricultural products (Defra, 2006). Fresh agricultural products include highly perishable crops (e.g. fresh fruits and vegetables) whose shelf-life can be measured in days, while non-perishable agricultural products are those that can be stored for longer periods of time. The ASC has some special characteristics that differentiates it from other food supply chain classifications (Foresight, 2011), such as limited shelf-life, importance of quality, and dependence on weather conditions (Luning et al., 2011; Tsolakis et al., 2014). Research in ASC relationships must consider commodity and supply chain stage specific characteristics (Fischer et al., 2010). The levels of collaboration in the ASC can be influenced negatively or positively by the nature of products, and the sector's structure (Matopoulos et al., 2007). Many authors studied ASC's special features which are related to product perishability, short shelf-life, seasonality, safety and quality variations (Zuurbier, 1999; Apte, 2010; Sharma et al., 2011; Dani and Kanwar, 2012). In particular, the perishable nature of the produce creates uncertainty with regards to food quality and safety compliance (Ruteri et al., 2009). Perishability, short shelf-life and quality variations are also causing PHFL (Kantor et al., 1997; Paull et al., 1997; Mena et al., 2011). These 
characteristics increase the complexity of ASC thus making it more difficult to manage than other supply chains. This also creates great challenge in minimizing food waste or PHFL especially with regards to highly perishable crops. In this study the PHFL is examined from the perspective of the highly perishable crops (i.e. peaches) with short shelf-life, and high quality variations and therefore the special features of the ASC are considered.

Hobbs et al. (2000) argue the need of shifting towards greater collaboration due to technological, regulatory, market and financial reasons in the ASC. Similarly, Matopoulos et al. (2007) emphasize the need for collaboration and claim the structure of the ASC and the nature of products have an impact on the nature of collaboration. A range of conceptual definitions have been used to define collaboration and in the context of this paper- supply chain collaboration. Broadly, supply chain collaboration is defined as "two or more chain members working together to create a competitive advantage through sharing information, making joint decisions, and sharing benefits which result from greater profitability of satisfying end customer needs than acting alone" (Simatupang and Sridharan, 2002, p. 258). Supply chain collaboration has also been defined as fundamental agreement among supply chain partners to integrate their resources for mutual gain (Bowersox et al., 2003). More recently, Cao et al. (2010, p. 6616) defined supply chain collaboration as: "a long-term partnership process where supply chain partners with common goals work closely together to achieve mutual advantages that are greater than the firms would achieve individually". This is the first comprehensive definition of collaboration from the firm's perspective from both process and relationship focuses. Also according to Cao et al. (2010) and Cao and Zhang (2011) collaboration includes seven inter-connected constructs which are: information sharing, goal congruence, decision synchronisation, incentive alignment, resource sharing, collaborative communication, and joint knowledge creation. Their comprehensive definition of collaboration is adopted here together with the sub-definitions of the collaboration constructs (the measures), but adapted to producer's unit of analysis rather than the firm's unit of analysis (Barratt, 2004) in order to fit the purpose of the current study. 


\subsection{Collaboration paradigms}

Different theories have been used to define, explain and describe collaboration in supply chains such as Transaction Cost Economics (TCE), Resource Dependence Theory (RDT), Resource Based View (RBV), and Contingency Theory (CT) (e.g. Hobbs and Young, 2000). According to TCE an organization collaborates with others in order to achieve efficiency through reduced transactional costs (Gray and Wood, 1991). Furthermore, RDT argues that organizations are constrained and affected by their environments and thus they act to attempt to manage resource dependencies (Hillman et al., 2009). RDT characterizes the links among organizations as a set of power relations based on exchange resources (Pfeffer et al., 2003). However, the collaboration - PHFL relationship may be better conceptualized using CT and RBV theories.

Specifically, CT suggests that organizational solutions are situational depending on the different changing environmental conditions (Wright and Ashill, 1996). CT aims to identify organizational designs or structures (i.e. the patterns of interactions among individuals) that promote organizational adaptation to environmental, technological and information processing contingencies (Zeithaml et al., 1988). Organizations that will identify those organizational designs will have a match with their environment and they could improve their performance easier than firms with a mismatch (Miles and Snow, 1974). ASC producers will seek to identify the appropriate organizational designs or else collaborative activities that will help them perform better and manage any changing environmental influences such as food product quality and food safety variations or changes better than others. The CT in this study is used in combination with the RBV theory as explained below in order to conceptualize the possible impact of the different collaborative activities needed for managing PHFL. Hence, CT highlights the importance of the different collaborative activities rather than collaboration as a single concept (see, for example, Simatupang et al, 2005; Scholten and Schilder, 2015).

In addition, RBV theory suggests that organizations enter a collaborative relationship to access and acquire resources, skills and knowledge from other organizations (Lee et al., 2001; Nieto and Santamaria. 2010; Sambasivan et al., 2013). It further argues that resources and capabilities 
provide firms with a competitive advantage that allows them to take advantage of opportunities and avoid threats or uncertainties in their business environment (Wernerfelt, 1984). Resources are all assets, capabilities, organizational processes, knowledge and capabilities controlled by an organization that enable the organization to be conceived of and implement strategies that improve its efficiency and effectiveness (Barney, 1991, p.101). Therefore, from the RBV perspective, ASC producers may seek to collaborate closer with potential partners to access and acquire resources, capabilities and skills to improve their performance i.e. PHFL. Thus, the collaboration - PHFL relationship could be conceptualized using the RBV theory.

ASC entities seek to collaborate with their partners as they realise that working together can get them substantial benefits which cannot be achieved by operating alone (Matopoulos et al., 2007). Collaboration in supply chains is important for innovation as partners realise a number of benefits of innovation such as high quality, lower costs, more timely delivery, efficient operations and effective coordination of activities (Soosay et al., 2008). Enhancing collaboration levels in ASCs has been seen as a source of competitiveness (Manzini and Accorsi, 2013). Firms enter in a relationship to extend their resources and acquire skills from their business partners (Sambasivan et al., 2013). However, there are many cases where firms struggled or failed to achieve collaboration and achieve its expected benefits (Fawcett et al., 2010). There are a number of challenges mentioned in the literature as impediments in achieving collaboration. The main barriers associated with collaboration are the following: difficulties in implementation, over-reliance on technological solutions, failure to differentiate with whom to collaborate with, and lack of trust between trading partners (Ramesh et al., 2008). Thus, collaboration in ASC may have positive and negative implications.

\subsection{Hypotheses development}

Recently a number of researchers (Mena et al., 2011; WRAP, 2011; WRAP 2015; FAO, 2014) have examined the PHFL from the consumers' and the retailers' perspective. Research has focused on behavioral change of consumers in order to reduce PHFL in the downstream supply chain (Parfitt et al., 2010, Quested et al, 2011). Also food reduction initiatives from the retailers' perspective have been explored (Otles et al., 2014); approaches have been developed for maximizing food retailers 
profit and reducing food waste (Wang and $\mathrm{Li}, 2012$ ) and strategies useful for retailers have been proposed against food waste and in the context of improving the sustainability of their business (Cicatelio et al., 2016).

There is, however, limited information in the academic literature on how to reduce and prevent PHFL in the upstream supply chain (Parfitt et al., 2010). Ways that have been proposed to reduce PHFL in the upstream supply chain concentrate mainly on the development of better infrastructure and storage facilities, adoption of new technologies, training provision to chain members, investment in cold chain facilities, handling equipment and formation of cooperatives (Choudhury, 2006; FAO, 2010; Hodges et al., 2010; Kader, 2010). However, along with the above mentioned enablers there is also a need for a change in people's behaviors to reduce PHFL (Andraski and Novack, 1996; Gattorna, 2006).

The lack of coordination among different actors in the upstream supply chain has a key role in contributing to PHFL (FAO, 2011). The interventions proposed to reduce PHFL in the upstream supply chain facilitate coordination, collaboration and transparency among food supply chain members. In particular, recent research showed that better supplier-retailer relations and collaborative action could possibly reduce PHFL (WRAP, 2011). As reported, the majority of the PHFL happens at the producers' point of the supply chain and therefore the producers' role in achieving PHFL reduction is crucial (FAO, 2012). Importantly, PHFL occurring from producer to buyer stage is estimated to be able to feed 1 billion people (Tomlinson, 2013). Although the collaboration - PHFL relationship from the producers' perspective and its importance have been speculated in some of the aforementioned studies, to the authors best knowledge there is no empirical investigation of the effect of collaboration on PHFL and business performance from the producers' perspective.

PHFL is a major challenge for ASC entities. Although ASC literature suggests that supply chain entities moved towards greater collaboration to cope with the new and upcoming challenges, it is not clear what are the appropriate nature and types of collaboration that will enable PHFL reduction. Collaboration is very broad and encompassing term and in the supply chain context where there are many entities together with a number of activities involved it can take different forms in order to maximise the success of it (Barratt, 2004). Because of this multidimensional nature the 
meaning of the collaboration cannot be captured by a single construct and different studies examined collaboration by considering different activities such as information sharing, joint performance measurement, joint planning, and joint problem solving (see Cao et al., 2010; Cao and Zhang, 2011; Vereecke et al., 2006). On the one hand, for example, information sharing, has been perceived as a key element of collaboration (Lee and Whang, 2001; Min et al., 2005; Sheu et al., 2006; Chopra and Meindl, 2007) that can facilitate the reduction in supply chain costs, and the achievement of competitive advantage (Cheng, 2011, Jain et al., 2009). On the other hand, other forms of collaborative relationships such as joint goal setting and planning are found to increase commitment and/or trust in the relationships (Min et al., 2005; Nyaga et al., 2010). However, empirical testing of the effect of different collaboration types on PHFL, in the ASC context, is missing from the literature. It can be argued, for example, that different types of collaboration with cooperatives can deliver different benefits to farmers such as for example reducing risk and costs, and increasing productivity and product quality. Hence, using disaggregate measure of collaboration allows for a better examination of the specific collaborative factors that can reduce PHFL. The approach of examining the effect of different collaborative activities rather than collaboration itself is in line with previous research (Simatupang et al, 2005; Scholten and Schilder, 2015).

In order to solve common agricultural problems and natural resource problems (e.g. the PHFL issue), ASC partners need to exploit, combine and complement each other's capabilities and work together (Pretty, 2008). A main challenge in the ASC is to develop collaborative relationships and to exploit partners' capabilities in order to increase the performance of the supply chain as a whole (Zuurbier, 1999). Also, the drivers of change in the ASC require upstream chain entities to develop and acquire new skills and knowledge in order to create new competences (Joshi et al., 2009). ASC members need to be educated to bridge the gap between local norms and international expectations (Roth et al., 2008). There is a need to develop the knowledge and the capabilities of ASC entities regarding food safety, food quality standards and appropriate usage of cold chain facilities to increase the productivity and the efficiency of the chain (FAO, 2014; Dani and Kanwar, 2012). Lack of knowledge on how to handle crops and the need for training provision to upstream chain members has been recognized as a main barrier in reducing PHFL (Hodges et al, 2010). In order to reduce PHFL, 
upstream chain members need to be educated and trained (Kader, 2010). Gaining access to acquire resources, skills and knowledge though a business partner could be a motivation to form a collaborative relationship. Therefore, ASC producers could gain new resources, skills and knowledge by entering in a more collaborative relationship such as the agricultural cooperative. By reducing PHFL, the business performance of all supply chain partners could be increased (Chapman, 2010). Based on the above, it is proposed that:

Hypothesis 1a: Collaboration between producers and agricultural cooperatives reduces the level of the PHFL.

Hypothesis 1b: Different types of collaboration - goal congruence, communication, information sharing, resource sharing, incentive alignment, decision synchronisation, joint knowledge creation between producers and agricultural cooperatives have different impact on the level of the PHFL.

\section{Research methodology}

\subsection{Data used}

In this research, the fresh peach agricultural product was selected as a representative product of the Greek fresh produce ASC. The data of this research was collected at the beginning of 2013, and the overall production and PHFL constructs are averaged over the past three years - covering periods of upward and downward fluctuations in peach production - to eliminate fluctuations in yearly production and PHFL levels and thus, reflect typical values. The actual number of Greek ASC peach producers is not registered anywhere, as producers in Greece are not classified as for example either peach or orange producers. Elstat (2011) provides information about the numbers of peach trees in different regions in Greece. The majority of peach trees are based in Central Macedonia $(699,731$ trees), Thessaly (29,376 trees), Western Macedonia (30,402 trees) and Eastern Macedonia (245 trees). Thus, the target population of this study is all the peach producers operating in the aforementioned geographical regions as these areas are representative of the whole population of peach producers in Greece. This means that the sample size of this study can be perceived as representative. The 
sampling frame is created by identifying lists of companies or customers lists (Lee and Lings, 2008). However, due to the non-existence of register with the contact details of all the Greek peach producers, the non-probability sampling technique was selected and the producers were approached through gatekeepers (i.e. members of cooperatives) at 180 different cooperatives located in the above regions.

The questionnaire was pre-tested and pilot-tested through a set of interviews with academics in the ASC area and producers, 20 and 25 respectively. This helped to enhance the clarity of the questionnaire, adapt accordingly the collaboration constructs to the ASC and producers unit of analysis, and validate the questionnaire (Hair et al., 2011). A face-to-face interview survey questionnaire method was chosen for the following reasons: (a) it enables the operationalization of the hypotheses formed and their subsequent empirical testing, (b) it gives access to a wide range of respondents by approaching them through the cooperatives that they collaborate, (c) it enables the collection of data regarding sensitive issues (i.e. how they collaborate with their partners and their PHFL levels), and finally (d) it allows the use of larger frame obtaining more generalizable results (Forza, 2002). Producers invited to participate in the face-to-face interview were provided in the first instance with a confidentially agreement, an informed consent form and also a summary of the research involved. To ease the process of filling in the questionnaire flashcards (i.e. cards with the scales for each listed question) were also used. A total of 2,000 producers were contacted through the gatekeepers of the cooperatives, and 220 agreed to participate (response rate $=11 \%){ }^{3}$ The duration of each face-to-face interview was thirty minutes, and the anonymity and confidentiality of the study was re-emphasised before the start of the interview.

Moreover, to avoid potential construct development error (see Simsen et al., 2010; Podsakoff et al., 2003; Podsakoff and Organ, 1986), the collaboration items (which are discussed in section 3.3), were carefully designed taking under consideration a number of elements including, for example, questionnaire pre-testing and pilot-testing, different scales and formats of responses in a

\footnotetext{
${ }^{3}$ Our sample size is in line with the recommended sample size using the method suggested by Green (1991). We have also used the accuracy in parameter approach to sample size suggested by Kelley and Maxwell (2003). The results suggest that a confidence interval with a half-width of 0.1 will require a sample size between 184 and 218.
} 
questionnaire, and negatively worded items (i.e. reverse coded items) to act as cognitive 'speed bumps' (Hinkin, 1995). ${ }^{4}$ Additionally, the predictor and the criterion variable were placed away from each other in the questionnaire so the respondents would not be able to make a connection between them and change their responses ${ }^{5}$.

In addition, first-order model measurement model was considered in order to be able to identify the effect of the different types of collaboration on PHFL. With the use of second-order measurement model (e.g. Cao and Zhang, 2011) information would have been lost about differences in the effects due to aggregation process.

\subsection{Dependent variables}

Following previous literature (e.g., Parfitt et al., 2010) the PHFL construct is measured in tonnes as an individual mean $\left(\overline{l_{l}}\right)$ over the past three years since the survey date (i.e. 2010-2012). Specifically, the Greek producers sort their production in two different categories, the 'A sorting' produce' and the 'B sorting' produce' categories; the sum of them gives the total producer's production. The 'A sorting' produce' category includes all the peaches that are sold either for processing or for selling them to consumers, while the 'B sorting produce' category is the wasted produce that is not being sold. We find that the overall PHFL mean $(\bar{l})$ is 12.69 tonnes, and that there are no differences between the means of 2010, 2011 and 2012 (prob.>F=0.35). The 'B sorting' produce' stands for the PHFL in the producers' language.

The above measure focuses on the level of the PHFL. Taking into account in the ASC that the production of food produced varies across producers and changes over time it is also interesting to examine whether collaboration between producers and cooperatives has a positive impact in reducing the proportion of food wasted. This ratio may also provide a proxy measure of producer's performance: a low ratio indicates that a small part of the production is lost after harvesting; a large ratio indicates that a significant part of the production is lost or the quality of the peaches is

\footnotetext{
${ }^{4}$ For the purpose of the analysis, the reverse coded items are transformed so that all the items of a questionnaire are coded in the same positive direction (Pallant, 2013). Finally, Cao et al. (2010) using similar constructs, conclude that common method bias is not a problem.

${ }_{5}^{5}$ More information about the research design and questionnaire is available in Despoudi (2016). Furthermore, the fit of the model is found to be improved by including seven factors rather than a single factor.
} 
deteriorated. To this end, it has been shown from the literature that facing uncertain environments, the supply chain collaboration influences firm performance (Cao and Zhang, 2011). Furthermore we are interested in examining whether the results reflect differences in the way the dependent variable is measured. Hence, we also estimate the proportion of low-quality peaches (type 'B') for each producer over the study period $\left(\bar{f}_{l}\right)$ to check whether or not collaboration makes significant contribution to the producer's performance. The overall mean $(\bar{f})$ is $11.39 \%$, and similarly we find no differences in performance over the study period (prob. $>\mathrm{F}=0.122$ ).

In Figure 1 we plot each value of the dependent variables against the fraction of the data that have values less than that fraction. Looking at panel (a) or panel (b) we observe that all the points are below the reference line suggesting that the PHFL distribution is skewed right.

[Figure 1 about here]

\subsection{Independent variables}

This paper is inspired by the work of Cao et al. (2010) and Cao and Zhang (2011) and thus uses a number of constructs measured on a 7-point Likert scale, with anchors ranging from 1= 'strongly disagree' to $7=$ 'strongly agree' to capture different perceived aspects of collaboration over the last three years' experience. Although Cao et al. (2010) and Cao and Zhang (2011) measures are comprehensive, they are based on the firm's unit of analysis and they are formative measures (composites) rather than reflective measures of collaboration. According to Law et al. (1998, p. 743), a formative construct "does not exist at a deeper conceptual level than its dimensions". The formative perspective treats a construct's items as being determinants of the latent variable: formative variables are defined by their items (Bagozzi and Fornell, 1982). While, reflective items are dependent on the value of a latent variable, with the latent variable determining the item scores (Bollen and Lennox, 1991). Thus, the seven constructs of collaboration have been adapted to the producers' unit of analysis and the items of each construct were reformed accordingly in an effort to provide a reflective meaning of each construct and new items were added to fulfil the purpose of this study i.e. identify collaboration types in the ASC relevant to producers. 
Hence, an exploratory factor analysis (EFA) is used to determine the underlying structure among the collaboration variables in the analysis. For confirming that factor analysis is suitable for the data reduction both the Kaiser-Meyer-Olkin $(\mathrm{KMO})$ measure of sampling adequacy $(\mathrm{KMO}=$ 0.969) and the Bartlett test of sphericity (p-value=0.000) are examined. Seven factors, with an eigenvalue greater that one, are retained (Kaiser, 1960). ${ }^{6}$ Table 1 presents the (varimax rotated factors) results using the principal-factor method including all factors loadings of 0.41 or above for easier reading (see Comrey and Lee, 1992). The seven factors are meaningful and explain 98.44 percent of the variance. ${ }^{7}$ Also, using disaggregate measures of collaboration allow us to identify types of collaboration that have stronger association with PHFL.

Specifically, the first factor $\left(c_{l}\right)$ captures the extent to which supply chain partners perceived own objectives are satisfied by accomplishing the supply chain objectives ('goal congruence'). The second factor $\left(c_{2}\right)$ loads most highly on contact and message transmission process among supply chain partners in terms of frequency, direction, mode, and influence strategy ('communication'). The third factor $\left(c_{3}\right)$ is a general 'information sharing' factor - the extent to which a firm shares a variety of relevant, accurate, complete and confidential ideas, plans, and procedures with its supply chain partners in a timely manner. The fourth factor $\left(c_{4}\right)$ loads most highly on the process of leveraging capabilities and assets and investing in capabilities and assets with supply chain partners ('resource sharing'). The fifth factor $\left(c_{5}\right)$ describes the process of sharing costs, risks, and benefits among supply chain partners ('incentive alignment'). The sixth factor $\left(c_{6}\right)$ mainly captures the process where supply chain partners orchestrate decisions in supply chain planning and operations that optimise supply chain benefits ('decision synchronisation'). The final factor $\left(c_{7}\right)$ captures the extent to which supply

\footnotetext{
${ }^{6}$ Reducing the number of factors increases the proportion of unexplained variation. We also performed an oblique rotation. The results are similar to the orthogonal rotation, but the loadings between items and factors are higher. However, the scores of the orthogonal part are used as explanatory variables in a subsequent multiple regression analysis to deal with multicollinearity problems (see Gatignon, 2004).

${ }^{7}$ In this context, the questionnaire comprises: (a) six items capturing information sharing (combined overall mean $=5.16, \alpha=0.991$ ), (b) seven items capturing goal congruence (combined overall mean $=4.29, \alpha=0.999$ ), (c) seven items capturing decision synchronisation (combined overall mean $=4.11, \alpha=0.978$ ), (d) seven items capturing incentive alignment (combined overall mean $=3.93, \alpha=0.994)$, (e) six items capturing resource sharing (combined overall mean $=3.95, \alpha=0.998$ ), (f) seven items capturing collaborative communication (combined overall mean $=5.16, \alpha=0.991$ ), and $(\mathrm{g})$ seven items capturing joint knowledge creation (combined overall mean $=4.03, \alpha=0.981$ ). Also, using the condisc command in Stata we find no problem with both convergent validity and discriminant validity.
} 
chain partners develop a better understanding of and response to the market and competitive environment by working together ('joint knowledge creation').

The last column of Table 1 shows the percentage of variance for the variable that is not explained by the common factors. Uniqueness is found to be low for all of the factor loadings suggesting that there is no considerable variability left over after considering the seven factors. We also find that there is a small and insignificant correlation between the extracted factors.

[Table 1 about here]

\subsection{Control variables}

We use a number of control factors in our paper. The unwillingness of the producers to change existing farming practices has been highlighted in the literature (Kaditi, 2010). In particular, Greek producers act based on their experience (Daoutopoulos and Pirovetsi, 2002). To account for this and within this context where the relative experience of the producers in farming may influence the way they treat their produce and might increase or decrease PHFL levels, the years of 'farming experience' is used as a control variable (mean=28.34).

Regarding the type of the peaches, there are two types of peaches: (a) table peaches (i.e. peaches sold straight for human consumption), and (b) processing peaches (i.e. peaches that go through processing in order to become a value added product such as canned peaches or marmalades). The table peaches due to the fact that they are sold directly to consumers they should have better appearance (e.g. being damage free, having nice shape and good size). Also, table peaches are more sensitive to insect infestation and they go through stricter inspections for any fertilisers left before being sold. Table peaches seem also to have higher profit margins for the producers, but because of the short shelf-life it is important that the produce is sold as soon as possible after its harvesting so that quality is maintained. On the other hand, processing peaches due to the fact that the main purpose of cultivating them is to have them processed, quality is not a major issue. Even when the produce is slightly damaged it can still be sold for processing. The profit margin of the producers selling processing peaches is very low. Therefore, we create a categorical variable to capture three types of 
peach production: 'table peaches only' (mean=58.33\%), 'peaches for processing only' $($ mean=2.32\%), and 'mixed table and processing types of peaches' (reference category, mean=39.35\%).

The age and education of the producers are other variables that might influence a person's decision-making. We can argue that older aged farmers might have a more old-fashioned and conservative thinking about business relationships or treatment of the produce. While, a younger-aged person might be more open to new ideas and new collaborations. The 'age' variable is measured in five different categories which are as follows: $(1)<31$ (reference category, mean=27.98\%), (2) 31-40 $($ mean=37.61\%), (3) 41-50 (mean=22.94\%) and $(5)>50($ mean=11.47\%). Regarding the education variable, we create a dichotomous variable taking the value of ' 1 ' if the producer has 'high-level qualification' (i.e. bachelor of above) (mean=11.52\%) and ' 0 ' if the producer has "low-level or no qualification" (mean=88.48\%).

Finally, we control for the farm size and geographical location. The farm size of peaches is measured in acres for this study (mean=64.36). As a farm grows in size, economies of scale may be obtained which in turn enhances performance. However, diseconomies of scale may start to occur after the farm size rises above a certain threshold level. We examine whether or not there is a nonlinear relationship between farm size and performance by including both a linear as well as a quadratic term of farm size in the model specification. There are three main peach production areas in Greece which are Central Macedonia (reference category, mean=82.57\%), Thessaly $(\operatorname{mean}=8.71 \%$ ) and Western Macedonia (mean=8.72\%), and we control for geographical location by including regional dummies in the regression model.

\section{Statistical approach}

The classical linear regression analysis summarizes the average relationship between a set of regressors and the dependent variable based on the conditional mean function. This paper, however, does not estimate the effect of the regressors on an average, but examines the effect of $c_{j, i}$ at the 
different points in the conditional distribution of $\bar{l}_{l} .{ }^{8}$ This is important from research and policy perspective, since there might be differences in the magnitude of $c_{j, i}$ at different quantiles, especially at the extremes of the distribution. Additionally, $\overline{l_{l}}$ is found to be not normally distributed, but skewed (see Figure 1) and therefore it justifies the use of quantile regression (Koenker and Bassett, 1978). ${ }^{9}$ To this end, we use a quantile regression to empirically examine how some specific quantile (including the 0.5 quantile) of PHFL, $\bar{l}_{l}$, responds to changes in collaboration, $c_{j, i}$, controlling for years of farming experience, types of peaches, age, education, farm size and geographical location.

Turning to the model of proportion of low-quality of peaches (type 'B'), we use a logistic quantile regression since $\bar{f}_{l}$ is bounded, where $\bar{f}_{l} \in\left(\bar{f}_{l_{\text {min }}}, \bar{f}_{l_{\text {max }}}\right)^{10}$. More detailed information about the methods employed here are provided in Appendix 1. Figure 2 outlines the conceptual model from which our hypotheses are tested.

[Figure 2 about here]

\footnotetext{
${ }^{8}$ Although it has been previously ignored in the literature, we acknowledge the possibility that the collaboration variable may be endogenous (for comprehensive discussion see Guide and Ketokivi, 2015). For example, the relationship between PHFL and collaboration is likely to reflect the impact of a third variable - e.g. collaboration may be correlated with unobserved personality traits of collaborative behaviour. Also, there may be the possible effect of simultaneity (e.g. higher levels of PHFL may lead to higher levels of collaboration). Although, the cross-sectional data used in this paper limits our efforts to explore this in depth, we experiment by estimating a 2 SLS and show that the effect of the bias is potentially small. Specifically, the survey allows us to extract information about the level of completion, and economic and political circumstances, and to use these variables as instruments. To allow for parameter identification, we include an averaged index of collaboration rather than the collaboration measures individually. Both Basmann's $(p$-value $=0.232)$ and Sargan's $(p$-value $=$ 0.213 ) tests do not reject the null hypothesis that the instruments are valid. Estimating a 2SLS produces an estimate of -4.802 which is similar to the uninstrumented equation (-4.688). Finally, both the Durbin (pvalue $=0.544)$ and $\mathrm{Wu}-$ Hausman ( $\mathrm{p}$-value $=0.558)$ tests do not reject the null of exogeneity. Hence, we proceed with our analysis treating collaboration variable as exogenous, but we encourage future research to examine this issue further within a longitudinal analysis framework.

${ }^{9}$ We have used the Shapiro -Wilk and Shapiro -Francia test statistics (Shapiro and Francia, 1972; Shapiro and Wilk, 1965). Both tests reject that $\bar{l}_{\iota}$ is normally distributed (p-value $\left.=0.000\right)$.

${ }^{10} f_{\min }\left(f_{\max }\right)$ are the minimum (maximum) value of the dependent variable minus (plus) half of the minimal increment of the dependent variable.
} 


\section{Results}

\subsection{Findings for the PHFL $\left(\overline{l_{l}}\right)$}

Table 2 presents the results of $\bar{l}$ model. Firstly we present the OLS (i.e. mean regression) as reference. ${ }^{11}$ The results show that there is a strong negative relationship between all types of collaboration and PHFL (the estimated coefficients range from -3.612 to -1.894 ), and thus hypothesis 1 is strongly supported. The support of this hypothesis significantly adds to the collaboration - PHFL relationship debate. In particular, our empirical results are in line with the suggested theoretical negative relationship between collaboration and PHFL reported in previous studies (Mena et al., 2011; WRAP, 2011) stressing the importance of collaboration as a way of reducing PHFL.

[Table 2 about here]

Importantly, we go beyond the existing literature and show that the magnitude of the coefficient varies significantly between different types of collaboration - we tested the equality of the coefficients and found that $\mathrm{F}(6,196)=4.01$, Prob $>\mathrm{F}=0.001$ - with 'resource sharing' having the stronger association with PHFL (coef.=-3.612). Similarly, 'goal congruence', 'information sharing' and 'incentive alignment' types of collaboration are found to significantly reduce PHFL. We test the hypothesis that the above collaboration variables have the same coefficient and find that the hypothesis cannot be rejected $[F(3,196)=0.45$, Prob $>F=0.716)]$. Hence, these types of collaboration are found to have the stronger association with PHFL suggesting that farmers gain from aligning their business objectives and sharing information, resources and risks with cooperatives. This finding is in line with previous work that finds that information sharing and joint efforts such as goal setting and sharing activities are among the most important variables affecting organisational

\footnotetext{
${ }^{11}$ We use the Breusch-Pagan / Cook-Weisberg test for heteroscedasticity. The results suggests that heteroskedasticity is present $\left[x^{2}(1)=6.88\right.$, Prob $\left.>x^{2}=0.009\right]$ making the use of quantile regression more appropriate than OLS. We also estimate a Tobit model since the dependent variable is left-censoring (Tobin, 1958). The Tobit regression coefficients are interpreted in the similar manner to OLS regression coefficients. We find that there is little difference between the OLS and Tobit estimates since we have only few leftcensoring observations (12.09\%). We test the hypothesis that the Tobit coefficients are equal to those reported from the OLS, and we find that the hypothesis cannot be rejected for all measures of collaboration (results are available upon request). Finally, in Table 1, Pseudo $\mathrm{R}^{2}$ is defined as square of the correlation between the fitted values and the dependent variable in the quantile regression and its value is not directly comparable to $R^{2}$.
} 
attitudes (e.g trust) and outcomes (Subramani and Venkatraman, 2003; Min et al., 2005; Nyaga et al., 2010). Statistically significant and negative coefficients are also found for 'communication', 'joint knowledge creation' and 'decision synchronization', but the coefficients are much smaller in size $[F(2,196)=0.10$, Prob $>F=0.902)] .{ }^{12}$ Since small farms dominate the Greek economy (Karantininis, 2017), we can argue that these types of collaborative practices maybe more important for larger sized farms that require more formal and regular channels of communication and synchronization in decision making, and are more likely to invest in research and development (R\&D) and innovation. ${ }^{13}$

Turning to the quantile regression we observe a negative and significant association between collaboration and PHFL in all quantiles. However, the latter technique seems to suggest that the magnitude of the estimated coefficients on different types of collaboration slightly varies over the conditional PHFL distribution. We test whether the estimated coefficients of different types of collaboration are the same at the 25 th, 50 th and 75 th quantiles, but the results indicate that there is no significant difference in the coefficients (suggesting that we can rely on OLS estimates) apart from the case of 'goal congruence' that is found to have statistically weaker effect in the lower quantile $(25 \%)$. Specifically, we test the equivalence of the quantile estimates of 'goal congruence' across quantiles and the result rejects equality of the estimated coefficients for the three quantiles in this case $[F(1,196)=3.58$, Prob $>F=0.029]$. Specifically, at the median (50\% quantile) the coefficient of "goal congruence" is 1.4 times larger than the estimated coefficient at the lower conditional quantile (25\%), although it slightly drops at the higher quantile (75\%). In other words "goal congruence" is of great importance for farmers experiencing high PHFL. We plot the quantile regression curves in Figure 3. The horizontal line refers to the OLS estimates, along with their confidence intervals. Generally, the plots suggest that OLS provides a comprehensive view of the collaboration and the level of PHFL relationship.

\footnotetext{
${ }^{12}$ When the factor scores from oblique rotation are used instead, we find that the coefficients of these variables to be statistically insignificant $(F(3,196)=0.25$, p-value $=0.861)$. Overall, the findings suggest that these types of collaboration are less likely to have an effect on PHFL.

${ }^{13}$ When we estimate the model separately for smaller and larger farms we find that the coefficients of "communication", "joint knowledge creation "and decision synchronization" increase substantially in the latter group. Testing the equality of the coefficients, we also find no differences between different forms of collaboration for this particular group $[\mathrm{F}(6,12)=0.82$, Prob $>\mathrm{F}=0.573]$.
} 
[Figure 3 about here]

Overall the above results suggest that different types of collaboration contribute towards lowering PHFL, but it is important to note that not all collaboration types have similar impact. In particular we find that 'goal congruence', 'resource sharing', , 'information sharing' and 'incentive alignment' are the most efficient forms of collaboration in terms of lowering PHFL, and the association of the former type of collaboration is found to lead to greater decline in PHFL at higher quantiles. Hence, the overall sample results provide strong support for $H I a$ and some support of $H 1 b$.

The results of the control variables are also interesting with 'mixed table and processing types of peaches' production shown to have higher PHFL compared to 'table peaches only' or 'peaches for processing only'. This suggests that specialisation in peach production may influence PHFL. Farming experience does not have a significant effect on PHFL, whereas some weak association is found between age and PHFL with those aged 41 to 50 to have higher PHFL than those below the age of 31 . Also, education is found to have a weak explanatory power across different specifications. We find an inverted U-shaped relationship between farm size and PHFL with the turning point to be about 146 acres. The effect of farm size becomes even stronger in the highest quantile. Finally, we find that Western Macedonia has lower PHFL than Central Macedonia and the coefficient becomes more than 2.5 times larger in magnitude in the $75^{\text {th }}$ quantile.

\subsection{Findings for the proportion of low-quality peaches $\left(\bar{f}_{l}\right)$}

So far we have focussed on the level of PHFL. Now we turn to examine the ratio of low-quality peaches to peach production to investigate whether the results hold when the dependent variable is modified. For this sensitivity analysis, we also consider three quantiles $q=\{0.25,0.50,0.75\}$, and the quantile regression results are presented in Table 3. These coefficients, however, can be interpreted in a similar way used for the interpretation of the coefficients of a logistic regression for binary outcomes. Although there is no immediate evidence for the role of collaboration in the lowest quantile 
(i.e. the middle of the lower half of the distribution $)^{14}$, the negative coefficients of different types of collaboration become statistically significant at the higher quantiles. We also test the joint null hypothesis that all the collaboration coefficients are simultaneously equal to zero for the 0.5 quantile $[F(7,196)=7.89 ;$ Prob $>F=0.000]$ and 0.75 quantile $[F(7,196)=11.37 ;$ Prob $>F=0.000]$. The test indicates a statistically significant association between collaboration and proportion of lowquality peaches. Hence, for those quantiles, the proportion of low-quality peaches decreases significantly with increasing collaboration levels. We also find that the differences in the coefficients of collaboration to be statistically significant within the median and 75 th quantile. ${ }^{15}$ Similar to our previous results, 'goal congruence', 'resource sharing', 'incentive alignment' and 'information sharing' are found to be of great importance for improving the quality of peach production. Therefore, this analysis provides further support to hypothesis $1 \mathrm{a}$ and hypothesis $1 \mathrm{~b}$.

[Table 3 about here]

In Figure 4 we plot the collaboration coefficient with its 95\% confidence interval for a dense set of quantiles. The figure shows that the coefficients of different types of collaboration decrease in absolute size as we move from the 0.05 onward, but level off at about the median quantile. In other words, producers with very low proportion of low-quality peaches are characterised by high levels of collaboration.

[Figure 4 about here]

Finally, we find that specialisation in peach production has a negative effect on the proportion of low-quality peaches. Age is found to be an important predictor at 0.75 quantile with older producers to be more likely to produce low quality peaches than younger producers. Farm size is estimated to have a negative effect, but we also find some evidence of non-linearity of farm size at

\footnotetext{
${ }^{14}$ The coefficients are also found to be jointly statistically insignificant $F(7,196)=0.15$, Prob $\left.>F=0.994\right]$.

${ }^{15} \mathrm{~F}(6,196)=4.07$, Prob $>\mathrm{F}=0.000$, and $\mathrm{F}(6,196)=3.13$, Prob $>\mathrm{F}=0.001$, respectively.
} 
0.75 quantile. Also, at 0.25 quantile of the proportion of low-quality peaches distribution, Western Macedonia has much stronger effect on expected proportion of low-quality peaches than at 0.75 quantile.

\section{Discussion}

This paper examined the effect of collaboration on the level of PHFL and proportion of low-quality peach production in the Greek ASC context. Based on the seminal work by Cao, et al. (2010) and Cao and Zhang (2011), this empirical study uses seven types of collaboration constructs to capture collaboration between producer and cooperative in 'information sharing', 'goal congruence', 'decision synchronisation', 'incentive alignment', 'resource sharing', 'collaborative communication; and 'joint knowledge creation', and examine their association with PHFL and low-quality peach production. The collaboration definitions are in line with the ones used by Cao et al. (2010), who was the first to provide a comprehensive measurement of the collaboration construct from the company's unit of analysis useful for researchers who investigate collaboration among supply chain partners. Our collaboration instruments borrowed, however, needed to be adapted to the producers' unit of analysis; thus conclusions from previous studies could not be directly applied as they are not problem specific. By doing this so, this study contributes in addressing a substantial research gap in the literature of the impact of collaboration and its types in the ASC on PHFL from the producers' unit of analysis in the ASC where the supply chain partners involved are producers and cooperatives aiming to empirically examine whether collaboration improves business performance from the producers' perspective. This study also contributes in the development and testing of a comprehensive, valid, and reliable measure of collaboration in ASC from the producers' perspective.

Hence, our findings are interesting and have important implications for academics, peach producers and policy makers. Identifying new ways to reduce PHFL is an important issue in the ASC research. This is because research in this area is still in its infancy and there are no clear conclusions on the factors that could reduce PHFL. Chapman (2010) referred to PHFL as a shrinkage problem and characterised it as a 'complex' problem that needs to be addressed with a collaborative manner. This research contributes to the body of knowledge of food supply chain management literature by 
increasing understanding of a complex problem i.e. PHFL issue and by proposing collaboration as a solution. The importance of collaboration as a solution to PHFL has been considered in the literature (Mena et al., 2011; WRAP, 2011), but it has never been empirically tested and proven to exist. This study's empirical findings suggest that higher levels of collaboration could lead to lower PHFL levels from the producers' unit of analysis with a unique dataset of Greek peach producers. In particular, we show that "goal congruence" with cooperatives is of great importance for farmers experiencing high PHFL (i.e. the effect of this type of collaboration has a larger negative impact on the higher quantiles of PHFL). Also, this study contributes to the academic literature in the PHFL research field. Since there is limited academic research and no data available in this area (Fusions, 2015), this study provided specific PHFL estimates as identified in the Greek ASC context. PHFL reduction means more effective usage of the natural resources and reduction of food waste going to landfill. Identifying new ways to reduce PHFL helps to preserve world's natural resources for the generations to come.

The findings of this study indicated that collaboration can reduce PHFL levels and improve business performance through better quality of peach production thus, more natural resources could be preserved as less food will be wasted and future generations are more likely to have access to sufficient quantity and quality of food. Importantly, the results depict that different types of collaboration have different effects on PHFL. In particular, we find that 'resource sharing', 'goal congruence', 'information sharing', and 'incentive alignment' to be among the most effective forms of collaboration. In other words, the findings of this research show that the different constructs of collaboration in ASC reflect its meaning and have an impact on PHFL. ASC entities need to rethink their collaborative practices in order to reduce their PHFL levels. For example, enhancing capabilities and assets shared between producers and cooperatives, aligning their goals, objectives and agenda, agreeing over sharing benefits, costs and risks, and exchanging knowledge and information can substantially improve small farm performance. As the farm grows, however, other forms of collaboration such as frequency and methods of communication, synchronization in decision making and information transmission, and joint knowledge and innovative development may become equally important to PHFL. Hence, these results provide a novel contribution to the academic literature regarding the collaborative practices that lead to better business performance (i.e. through PHFL 
reduction) from the producers' perspective and contributes to existing collaboration - performance literature (Hyvönen and Tuominen, 2007; William and Filippini, 2009). It has overall been confirmed that collaboration needs to be context specific and in ASC it can bring benefits for PHFL reduction.

Additionally, the type of the peaches is found to impact the PHFL levels. In particular, producers who produce both 'table and processing types of peaches' seem to have higher PHFL levels. Thus, producers who focus only on producing one type of peaches may have lower PHFL levels. Also, farming experience found to have no impact on PHFL levels. The Greek ASC producers act based on their experience and they are not willing to adopt new farming practices (Daoutopoulos and Pirovetsi, 2002), however, this found not to influence a lot the levels of PHFL that they have. The findings of this study suggested that younger aged producers have lower PHFL levels than older aged producers. Therefore, although farming experience may not impact the levels of PHFL the age of the producers should be considered. In contrast, farm size found to have a significant effect on PHFL. Large-scale farms have higher profits and have better environmental and societal performance than small-scale farms (Van der Meulen et al., 2014). Hence, the findings of this study is in line with previous research and add to the existing literature by empirically proving that farm size has an impact on the environmental performance of a particular production.

The overall quantile regression estimates suggest that better performed producers owe much of their success to collaborative synergies. Thus, our study raises awareness of the impact of collaboration on PHFL and producer's performance in ASC. In particular, ASC entities need to rethink their collaborative practices in order to reduce their PHFL levels and boost performance. Policy-makers are also called to find ways to encourage the formation of collaborative practices in ASCs and stimulate growth in the sector. The identification of the best collaborative practices, which can improve business performance and encourage healthy and long-lasting collaborations, remains a challenge for ASC entities, food supply chain entities and supply chain managers. 


\section{Conclusion and directions for future research}

In summary, this study contributes to both theory and practice and adds to the collaboration - PHFL relationship in ASC from the producers' perspective with two important findings; firstly, collaboration reduces both the level of PHFL and the low-quality of fruit crop. Secondly, specific types of collaboration - 'resource sharing', 'goal congruence', 'information sharing' and 'incentive alignment' - are likely to translate into greater PHFL reduction, and help to minimise low-quality peach production.

Although our paper makes significant contribution to literature by unpacking the relationship between collaboration and PHFL from the producers' unit of analysis, it does come with certain limitations but also provides avenues for future investigations.

From theoretical perspective, additional measurement of collaboration in ASC should also be explored in the future research. This research adapted Cao et al.'s (2010) measures and terminology to the producers' unit of analysis in ASC. The collaboration measure in ASC as developed in this study provides a basis for further research into the collaboration measurement in other EU ASCs and food supply chains and from different units of analysis (e.g. processors, wholesalers, retailers). Data from both producers and cooperatives sides should be collected by future research to enrich the depth of the analysis and eliminate any bias concerns; however, operational difficulties may frustrate this task. Also, future research can build on our results to deepen the theoretical understanding of the different types of collaboration and their association with PHFL.

From empirical perspective, longitudinal and larger scale studies, considering different markets and wider regulatory, along with cultural and individual, characteristics can shed more light on the collaboration - PHFL nexus. Also, there are may be some important environmental and regulatory factors that can change the nature and types of collaboration. All these are important issues that deserve further analysis, and we leave this as future work. In addition, the proposed analysis could be checked for its generalizability to other Greek ASC products. Hence, future research may reveal whether the results of this study are generalizable to Greece as a whole and to other EU ASCs including other agricultural products, and with different units of analysis (e.g. processors, wholesalers, 
retailers). Finally, future research could also consider measuring the economic loss of PHFL and measuring PHFL levels for different agricultural and other food products.

\section{Acknowledgements}

We would like to thank Baibing Li (Professor of Business Statistics and Management Science at Loughborough University) and the three anonymous referees for useful comments and discussions. We also like to thank conference participants at 3rd International Conference on Green Supply Chain for helpful suggestions. 


\section{References}

Alexandratos, N. and Bruinsma, J. (2012), "World Agriculture Towards 2030/2050: the 2012 Revision”, ESA Working Paper, Nr.12-03, FAO, Rome.

Andraski, J.C. and Novack, R.A. (1996), "Marketing logistics value: managing the 5P's", Journal of Business Logistics, Vol. 17, Issue 1, pp. 23-34.

Apte, A. (2010) "Supply chain networks for perishable and essential commodities: design and vulnerabilities", Journal of Operations and Supply Management", Vol.3. Issue: 2, pp. 26-43.

Aramyan, L.H. and Van Gogh, J.B. (2014), "Reducing postharvest food losses in developing economies by using a Network of Excellence as an intervention tool", Presented in the IFAMA 2014 and CCA Food and Agribusiness World Forum 'People Feed the World' in Cape Town, South Africa, June, available at http://www.ifama.org/files/conf/papers/988.pdf. (Accessed 12 Oct 2015).

Bagozzi, R.P. and Fornell, C. (1982), “Theoretical concepts, measurements, and meaning”. In C. Fornell (Ed.), A second generation of multivariate analysis, Vol. 2, pp. 24-38, New York: Praeger Publishers.

Barratt M., (2004), "Understanding the Meaning of Collaboration in the Supply Chain, Supply Chain Management: An International Journal", Vol. 9, Issue 1, pp. 30-42.

Barney, J.B. (1991), "Firm resources and sustained competitive advantage", Journal of Management, Vol. 17, pp. 99-120.

Borodin, V., Bourtembourg, J., Hnaien, F. and Labadie, N. (2014), "A quality risk management problem: case of annual crop harvest scheduling”, International Journal of Production Research, Vol. 52, Issue 9, pp. $2682-2695$.

Bollen, K. and Lennox, R. (1991), "Conventional wisdom on measurement: A structural equation perspective”, Psychological Bulletin, Vol. 110, Issue 2, pp. 305-314.

Bottai, M., Cai, B. and McKeown, R.E. (2009), "Logistic quantile regression for bounded outcomes", Statistics in Medicine, Vol. 29, Issue 2, pp. 309-317

Bowersox, D., Closs, D. and Stank, T. (2003), "How to Master Cross-Enterprise Collaboration", Supply Chain Management Review, Vol. 7, Issue 4, pp. 18-27. 
Business Continuity Institute (2013), "Supply Chain Resilience Trends 2009-2013 Surveys", Business Continuity Institute in partnership with CIPS, and Zurich Insurance, available at http://www.bcifiles.com/BCI_ROSCR.pdf (Acessed 10th Oct, 2017).

Cao, M., Vonderembse, M.A., Zhang, Q. and Ragu-Nathan, T.S. (2010), "Supply chain collaboration: conceptualisation and instrument development", International Journal of Production Research, Vol. 48, Issue 22, pp. 6613-6635.

Cao, M., and Zhang, Q. (2011), Supply chain collaboration: Impact on collaborative advantage and firm performance, Journal of Operations Management, Vol, 29, pp. 163-180.

Chapman, P. (2010), "Reducing Product Losses across the Food Supply Chain" in: Mena, C. and Graham, S. Delivering Performance in Food Supply Chains, Woodhead Publishing.

Cheng, J.-H (2011), "Inter-organizational relationships and information sharing in supply chains", International Journal of Information Management, Vol. 31., Issue: 4 pp. 374-384.

Chopra, S. and Meindl, P. (2007), Supply chain management: strategy, planning and operation, Upper Saddle River, New Jersey: Pearson.

Choudhury, M.L. (2006), "Recent development in reducing postharvest losses in the Asia-Pacific region", in Postharvest management of fruit and vegetables in the Asia-Pacific region, APO.

Christopher, M., and Holweg, M. (2011), "Supply chain 2.0": managing supply chains in the era of turbulence, International Journal of Physical Distribution Logistics Management, Vol. 41, Issue 1, pp. 63-82.

Cialdella, N., Dobremez, L. and Madelrieux, S. (2009), "Livestock farming systems in urban mountain regions: differentiated paths to remain in time", Outlook on Agriculture, Vol. 38, No. 2, pp. $127-135$.

Cicatelio, C., Franco, S., Pancino, B. and Blasi, E. (2016), “The value of food waste: An exploratory study on retailing”, Journal of Retailing and Consumer Services, Vol. 30, pp. 96-104.

Comrey, R. O. and Lee, H. B. (1992), “A First Course in Factor Analysis" (2nd Ed.). Hillsdale, NJ: Erlbaum.

Danese P., (2011), “Towards a contingency theory of collaborative planning initiatives in supply networks", International Journal of Production Research, Vol.49, Issue 4, pp. 1081-1103. 
Dani, S. and Kanwar, B. (2012), "Sustainability and Risk Challenges in food supply chains: an Indian perspective", Cambridge- IIML UKIERI, UK.

Daoutopoulos, G.A. and Pirovetsi, M. (2002), "Sustainable agriculture: the vision of Greek agriculture, in Agriculture and Livestock magazine", Issue 1, available at http://www.agrotypos.gr/magazine/index.asp?mod=arthra\&MagAA=90\&ContIndex=9\&id=49

(Accessed 10 February 2013) (in Greek).

Defra., (2006), "Food Industry Sustainability Strategy", available at http://www.defra.gov.uk/publications/files/pb11649-fiss2006-060411.pdf (Accessed 10 September 2014).

De Silva, M. Howells, J. and Meyer, M. (2017), "Innovation intermediaries and collaboration: Knowledge-based practices and internal value creation", Research Policy, http://dx.doi.org/10.1016/j.respol.2017.09.011, In press.

Despoudi, S. (2016), “An Investigation of the Collaboration - Postharvest Food Loss Relationship and the Effect of the Environmental Turbulence Factors", Loughborough University, available at https://dspace.lboro.ac.uk/dspace-jspui/bitstream/2134/21785/1/Thesis-2016-Despoudi.pdf

Diabat, A., Govindan, K. and Panicker, V.V. (2011), "Supply chain risk management and its mitigation in food industry", International Journal of Production Research, Vol. 50, No. 11, pp. 3039-3050.

EEFP., (2014), "Conditions, attitudes and structures of successful POs and cooperatives", available at https://ec.europa.eu/agriculture/sites/agriculture/files/agri-markets-task-force/contributions/2016-0524/ukdefracoop_en.pdf (Accessed 1 June 2017).

Elstat, (2011), “Agriculture Statistic of Greece year 2006-2011”. Elstat Internally Requested data. European Union., (2016), "EU platform on food losses and food waste", available at http://ec.europa.eu/food/safety/food_waste/eu_actions/eu-platform/index_en.htm (Accessed 5 June 2016).

Eurostat., (2016), "The fruit and vegetable sector in the EU - a statistical overview ", available at http://ec.europa.eu/eurostat/statistics- 
explained/index.php/The_fruit_and_vegetable_sector_in_the_EU_-

_a_statistical_overview\#Data_sources_and_availability (Accessed 1 June 2017).

FAO., (2010), "FAO / World Bank workshop on reducing post-harvest losses in grain supply chain in

Africa", available at

http://www.fao.org/fileadmin/user_upload/ags/publications/FAO_WB_ph_web.pdf (Accessed 19

February 2012).

FAO., (2011), "Global Food Losses and Waste”, available at

http://www.fao.org/fileadmin/user_upload/ags/publications/GFL_web.pdf $\quad$ Accessed 10 January 2012).

FAO., (2012), “Commodities by country", available at

http://faostat.fao.org/DesktopDefault.aspx?PageID=339\&lang=en\&country=84 (Accessed 4 June 2014).

FAO., (2013a), "Food wastage footprint: impacts on natural resources. Summary report, Rome.", available at http://www.fao.org/docrep/018/i3347e/i3347e.pdf (Accessed 4 June 2014).

FAO., (2013b), "Toolkit: reducing the food wastage footprint", available at http://www.fao.org/docrep/018/i3342e/i3342e.pdf (Accessed 4 June 2014).

FAO., (2014), "Mitigation of Food Wastage: Societal Costs and Benefits", available at http://www.fao.org/3/a-i3989e.pdf (Accessed 1 June 2017).

Fawcett, S.E., Magnan, G.M. and Fawcett, A.M. (2010), "Mitigating resisting forces to achieve the collaboration-enabled supply chain”, Benchmarking: An International Journal, Vol. 17, Issue 2, pp. $269-293$.

Fink, M., Harms, R. \& Kraus, S. (2008). Cooperative internationalization of SMEs: Self-commitment as a success factor for international entrepreneurship. European Management Journal, 26, 429-440.

Fischer C., Hartmann M., Reynolds, N., Leat, P., Revoredo-Giha, C., Henchion, M., Albisu, L.M. and Gracia, A. (2010), "Factors influencing contractual choice in European agri-food supply chains", European Review of Agricultural Economics, Vol.36, No. 4, pp. 541-569. 
Foresight., (2011), "Foresight Project on Global Food and Farming Futures. Synthesis Report C7: Reducing Waste", The Government Office for Science: London.

Forza, C. (2002), "Survey research in operations management: a process based perspective", International Journal of Operations \& Production Management, Vol. 22, Issue 2, pp. 152-194.

Fusions (2015), "Review of current EU Member States legislation and policies addressing food waste", available at http://www.eu-fusions.org/phocadownload/Reports/GREECE\%20FULL\%20pdf.pdf $\quad$ Accessed 10 October 2015).

Gatignon, H. (2004), “Statistical Analysis of Management Data”, Boston: Kluwer. Gattorna, J. (2006), “Living Supply Chains”, London: Prentice Hall.

Golini, R. Moretto, A., Caniato, F. Caridi, M. and Kalchschmidt, M. (2017), "Developing sustainability in the Italian meat supply chain: an empirical investigation", International Journal of Production Research, Vol. 55, Issue 4, pp. 1183-1209.

Golonka, M. (2015), "Proactive cooperation with strangers: Enhancing complexity of the ICT firms' alliance portfolio and their innovativeness", European Management Journal, 33, 168-178.

Gray, D.J. and Wood, B. (1991), "Collaborative Alliances: Moving from Practice to Theory", The Journal of Applied Behavioral Science, Vol. 27, Issue 3, pp. 22.

Green, S.B. (1991), "How many subjects does it take to do a regression analysis", Multivariate Behavioral Research, Vol. 26 No. 3, pp. 499-510.

Guide, V.R.D. and Ketokivi, M. (2015), "Notes from the editors: Redefining some methodological criteria for the journal", Journal of Operations Management, 37, v-viii.

Gustavsson, J., Cederberg, C., Sonesson, U., Otterdijk, R. and Meyberg A. (2011), “Global Food Losses and Waste", available at http://www.fao.org/fileadmin/user_upload/ags/publications/GFL_web.pdf $\quad$ Accessed 10 January 2012).

Hair, J.F.Jr., Wolfinbarger C., Money A.H., Samouel P. and Page M.J. (2011), "Essentials of Business Research methods", 2nd ed., New York: Sharpe. 
Halloran, A., Clement, J., Kornum, N., Bucatariun, C. and Magid, J. (2014), “Addressing Food Waste in Denmark", Food Policy, Vol. 49, pp. 294 - 301.

Hillman, A.J., Withers, M.C. and Collins, B.J. (2009), "Resource Dependence Theory: A Review", Journal of Management, Vol. 35, Issue 6, pp. 1404-1427.

Hinkin, T.R. (1995), “A review of scale development practices in the study of organizations", Journal of Management, Vol. 21, No. 5, pp. 967-988.

Hobbs, J.E.,and Young, L.M. (2000), "Closer vertical co-ordination in agri-food supply chains: a conceptual framework and some preliminary evidence", Supply Chain Management: An International Journal, Vol. 5, Issue 3, pp.131- 143.

Hodges, R., Buzby, J.C. and Benett, B. (2010), "Postharvest losses and waste in developed and less developed countries: opportunities to improve resource use", Journal of Agricultural Science, Cambridge University, available at http://ucanr.edu/datastoreFiles/234-2203.pdf (Accessed 30 January 2017).

Hovelaque, V., Duvaleix-Triguer, S. and Cordier, J. (2009), "Effects of constrained supply and price contracts on agricultural cooperatives", European Journal of Operational Research, Vol. 199, Issue 3, pp. $769-780$.

Hyvönen, S. and Tuominen, M. (2007), "Channel Collaboration, Market Orientation and Performance Advantages: Discovering Developed and Emerging Markets", The International Review of Retail, Distribution and Consumer Research, Vol. 17, Issue 5, pp. 423-445.

Jain, V., Wadhwa, S., and Deshmukh, S. G. (2009), "Revisiting information systems to support a dynamic supply chain: issues and perspectives", Production Planning and Control, Vol. 20, No. 1, pp. $17-29$.

Joshi, R., Kumar D.B. and Hankar, R. (2009), "Indian cold chain: modelling the inhibitors", British Food Journal, Vol. 111, Issue 11, pp.1260 - 1283.

Kader, A.A. (2010), "Handling of Horticultural Perishables in Developing vs. Developed Countries", Proceedings of the $6^{\text {th }}$ International Postharvest Symposium, available at http://ucce.ucdavis.edu/files/datastore/234-1875.pdf (Accessed 10 January 2012). 
Kaditi, E.A. and Nitsi, E.I. (2010), "The agricultural sector in Greece, Centre of Planning and Economic Research (KEPE)”, Athens, Greece (in Greek).

Kaiser, H.F. (1960), "The application of electronic computers to factor analysis", Educational and Phychological Measurement, Vol. 20, pp. 141-151.

Kantor, L.S., Lipton, K., Manchester, A. and Oliveira, V. (1997), "Estimating America's food losses", Food Review, Vol. 20, Issue, 1, pp. 2-12.

Karantininis, K. (2017), “A New Paradigm for Greek Agriculture”, Springer.

Kelley, K. and Maxwell, S.E. (2003). "Sample Size for Multiple Regression: Obtaining Regression Coefficients That Are Accurate, Not Simply Significant”, Psychological Methods, 8(3), pp. 305-321.

Kenneth, W., Green, Jr., Pamela, J., Zelbst, V.S. and Bhadauria, J. (2012), "Do environmental collaboration and monitoring enhance organizational performance?", Industrial Management \& Data Systems, Vol. 112, Issue 2, pp. 186-205, doi: 10.1108/02635571211204254.

Koenker, R. and Bassett, G. (1978), “Regression Quantiles”, Econometrica, Vol. 46, Issue: 1, pp. $33-$ 50.

Koenker, R. and Hallock, K. F. (2001), "Quantile Regression”, Journal of Economic Perspectives, Vol. 15, Issue 4, pp. 143-156.

Kummu, M., de Moel, H., Porkka, M., Siebert, S., Varis, O. and Ward, P.J. (2012) "Lost food, wasted resources: Global food supply chain losses and their impacts on freshwater, cropland, and fertiliser use", Science of The Total Environment, Vol. 438, Issue 1, pp. 477 - 489.

Lee, C., Lee, K., and Johannes, M.P. (2001), "Internal capabilities, external networks, and performance: A study on technology-based ventures", Strategic Management Journal, 22, 615-640.

Lee, N. and Lings, I. (2008), "Doing Business Research: a guide to theory and practice”, Los Angeles, Thousand Oaks: Sage Publications Inc.

Lee, H.L. and Whang, S. (2001), E-business and supply chain integration, Stanford Global Supply Chain Management Forum, SGSCMF-W2-2001.

Law, K.S., Wong, C.S. and Mobley, W.H. (1998), "Toward a taxonomy of multidimensional constructs", Academy of Management Review, Vol. 23, pp. 741-755. 
Luning, P.A., Marcelis, W.J., Rovira, J., Van Boekel, M.A.J.S., Uyttendaele, M. and Jacxsens L. (2011), "A tool to diagnose context riskiness in view of food safety activities and microbiological safety output", Trends in Food Science \& Technology, Vol. 22, Issue 1, pp. 67-79.

Manos C., and Manikas I., (2010), "Traceability in the Greek fresh produce sector: drivers and constraints", British Food Journal, Vol. 112, Issue 6, pp. 640-652.

Manzini, R. and Accorsi, R. (2013), "The new conceptual framework for food supply chain assessment", Journal of Food Engineering, Vol. 115, Issue 2, pp. 251-263.

Matopoulos, A., Vlachopoulou, M., Manthou, V. and Manos, B. (2007), “A Conceptual Framework for Supply Chain Collaboration: Empirical Evidence from the Agri-food Industry", Supply Chain Management: An International Journal, Vol. 12, Issue 3, pp. 177-186.

Mena, C., Adenso-Diaz, B. and Yurt, O. (2011), "The causes of food waste in the supplier-retailer interface: Evidences from UK and Spain, Resources", Conservation and Recycling, Vol. 55, pp. 648658.

Miles, R.E. and Snow, C.C. (1974), Fit, Failure, and the Hall of Fame, Free Press, New York.

Min, S., Roath, A.S., Daugherty, P.J., Genchev, S.E., Chen, H., Arndt, A.D., and Richey, R.G. (2005), "Supply chain collaboration: what's happening?", The International Journal of Logistics Management, Vol. 16, Issue 2, pp. 237-256.

Nakandala, D., Lau, H. and Zhao, L. (2017), “Development of a hybrid fresh food supply chain risk assessment model", International Journal of Production Research, Vol. 55, Issue 14, pp. 4180-4195. Nieto, M.J., and Santamaria, L. (2010), “Technological collaboration: Bridging the innovation gap between small and large firms", Journal of Small Business Management, 48(1), 46-71.

Nyaga, G.N., Whipple, J.M. and Lynch, D.F. (2010), "Examining supply chain relationships: do buyer and supplier perspectives on collaborative relationships differ?", Journal of Operations Management, Vol. 28 No. 2, pp. 101-114.

Pallant, J. (2013), SPSS Survival Manual: A step by step guide to data analysis using IBM SPSS, $5^{\text {th }}$ ed., Berkshire: Open University Press. 
Parfitt, J., Bartherl, M. and Macnaughton, S. (2010), "Food Waste within Food Supply Chains: Quantification and Potential for Change to 2050", Philosophical Transactions of the Royal Society B, Vol. 365, pp. 3065-3081.

Paull, R. E., Nishijima, W., Reyes, M. and Cavaletto, C. (1997), "Postharvest handling of losses during marketing of papaya", Postharvest Biology and Technology, Vol.11, Issue 3, pp.165-179. Pfeffer, J. and Salancik, G.R. (2003), The external control of organizations: A resource dependence perspective, Stanford: Stanford University Press.

Podsakoff P.M., and Organ D.W., (1986), "Self-reports in organizational research: Problems and prospects", Journal of Management, Vol. 12, Issue 4, pp. 531-544.

Podsakoff, P.M., MacKenzie, S.B., Lee J., and Podsakoff, N.P. (2003), "Common method biases in behavioural research: A critical review on the literature and recommended remedies", Journal of Applied Psychology, Vol. 88, Issue 5, pp. 879-903.

Pretty, J. (2008), “Agricultural sustainability: concepts, principles and evidence”, Philosophical Transactions Research Society, Vol. 363, pp. 447-465.

Quested, T.E., Parry, A.D., Easteal, S. and Swannell, R. (2011), Food and drink waste from households in the UK, Vol 36, pp. 460-467.

Ramesh, A., Banwet, D.K. and Shankar R. (2010), "Modelling the Barriers of Supply Chain Collaboration”, Journal of Modelling in Management, Vol. 5, Issue 2, pp. 176-193.

Roth, A.V., Tsay, A.A., Pullman, M.E. and Gray J.V. (2008), "Unraveling the food supply chain: strategic insights from China and the 2007 recalls", Journal of Supply Chain Management, Vol. 44, Issue 1, pp. 22-39.

Sambasivan, M., Siew-Phaik, L., Abidin, Mohamed Z. and Choy Leong Y. (2013), "Factors influencing strategic alliance outcomes in a manufacturing supply chain: Role of alliance motives, interdependence, asset specificity and relational capital", International Journal of Production Economics, Vol. 141, Issue 1, pp. 339-351.

Shapiro, S.S. and Francia, R.S. (1972), "An approximate analysis of variance test for normality”, Journal of the American Statistical Association 67, 215. 
Shapiro, S.S. and Wilk, M.B. (1965), "An analysis of variance test for normality (complete samples)", Biometrika 52, pp. 591-611.

Sharma, G. and Singh, S.P. (2011), "Economic analysis of post-harvest losses in marketing of vegetables in Uttarakhand", Agricultural Economics Research Review, Vol. 24, pp. 309-315.

Simatupang, T.M. and Sridharan, R. (2002), “The collaborative supply chain", The International Journal of Logistics Management, Vol. 13, Issue 1, pp. 15-30.

Simsen E., Roth A., and Oliveira P., (2010), "Common method bias in regression models with linear, quadratic and interaction effects”, Organizational Research Methods, Vol. 13, Issue 3, pp. 456-476.

Singh, P J. and Power D. (2009), "The Nature and Effectiveness of Collaboration between Firms, their Customers and Suppliers: A Supply Chain Perspective", Supply Chain Management: An International Journal, Vol. 14, Issue 3, pp.189-200.

Scholten, K. and Schilder, S, (2015), "The role of collaboration in supply chain resilience", Supply Chain Management: An International Journal, Vol. 20 Issue: 4, pp. 471- 484.

Soosay, C.A., Hyland, P.W. and Ferrer, M. (2008), "Supply chain collaboration: capabilities for continuous innovation", Supply Chain Management: An International Journal, Vol. 13, Issue 1, pp. 160-169.

Sheu, C., Yen, H., and Chae, D. (2006), "Determinants of supplier-retailer collaboration: evidence from an international study", International Journal of Operations \& Production Management, Vol 26, No. 1, pp. 24-49.

Shukla, M. and Jharkharia, S. (2013), “Agri-fresh produce supply chain management: a state of the art literature review", International Journal of Operations \& Production Management, Vol. 33 Issue: 2, pp. 114-158.

Simatupang, T. M. and Sridharan, R. (2005), "The collaboration index: a measure for supply chain collaboration", International Journal of Physical Distribution \& Logistics Management, Vol. 35, Issue: 1, pp. 44-62.

Spence, M.M., Manning, L.M. \& Crick, D. (2008), “An investigation into the use of collaborative ventures in the internationalization of high-performing Canadian SMEs", European Management Journal, 26, 412-428. 
Stank T.P., Keller S.B., \& Daugherty P.J., 2001, "Supply chain collaboration and logistical service performance", Journal of Business Logistics, Vol. 22, Issue 1, pp. 29 - 48.

Subramani, M. and Venkatraman, N., 2003, Safeguarding investments in asymmetric interorganisational relationships: theory and evidence, Academy of Management Journal, 46, pp. 4662.

Otles, S, Despoudi, S, Bucatariu, C. and Kartal, C. (2014), "Food Waste Production and Sustainability in the Food Industry", Chapter 1, in the book Food Waste Recovery: Processing Technologies and Techniques edited by Charis Galanakis, published by Elsevier.

Ruteri J.M., and Xu Q., 2009, Supply Chain Management and Challenges Facing the Food Industry Sector in Tanzania, International Journal of Business and Management, Vol. 4, Issue 12, pp. 22-28. The World Bank., (2011), "Missing Food: the case of postharvest grain losses in Sub-Saharan Africa", available at http://siteresources.worldbank.org/INTARD/Resources/MissingFoods10_web.pdf $\quad$ (Accessed 26 December 2012).

Tobin, J. (1958), "Estimation of relationships for limited dependent variables", Econometrica, Vol. 26, No. 1, pp. 24-36.

Tomlinson, I. (2013), "Doubling food production to feed the 9 billion: a critical perspective on a key discourse of food security in the UK", Journal of Rural Studies, 29, pp. 81-90.

Tsolakis, NK., Keramydas, C.A., Toka, S.K., Aidonis, D.A. and Iakovou, E.T. (2014), "Agrifood supply chain management: A comprehensive hierarchical decision-making framework and a critical taxonomy", Biosystems Engineering, Vol. 120, pp. 47 - 64.

Van der Meulen, H.A.B., Dolman, M.A., Jager, J.H. and Venema G.S. (2014), “The impact of farm size on sustainability of Dutch dairy farms", International Journal of Agricultural Management, Vol. 3, Issue 2, pp. 119-124.

Van der Vorst, J.G.A.J., Tromp, S.O. and Vann der Zee, D.K. (2009), "Simulation modelling for food supply chain redesign; integrated decision making on product quality, sustainability and logistics", International Journal of Production Research, Vol. 47, Issue 23, pp. 6611 - 6631. 
Vereecke, A. and Muylle, S. (2006), "Performance improvement through supply chain collaboration in Europe", International Journal of Operations \& Production Management, Vol. 26, Issue 11 pp. 1176- 1198.

Wang, X. and Li, D. (2012), A dynamic product quality evaluation based pricing model for perishable food supply chains, Omega, Vol. 40, Issue 6, pp. 906-917.

Wernerfelt, B. (1984), “A resource-based view of the firm”, Strategic Management Journal, Vol. 5, pp. 171-180.

William, H.A.J. and Filippini, R. (2009), "Collaboration practices, strategic capabilities and performance in Japanese and American product development: Do they differ?", Operations Management Research, Vol. 3, Issue 1-2, pp. 22-32.

WRAP (2011), "Reducing Food Waste through Retail Supply Chain Collaboration”, available at http://www.wrap.org.uk/sites/files/wrap/WRAP IGD supply chain report.pdf (Accessed 30 January 2017).

WRAP (2015), "Household food waste in the UK, 2015", available at http://www.wrap.org.uk/sites/files/wrap/Household_food_waste_in_the_UK_2015_Report.pdf (Accessed 25 June 2017).

Wright, M. and Ashill, N. (1996), "A contingency model of marketing information", European Journal of Marketing, Vol. 32, Issue 1/2, pp. 125-144.

Zeithaml, V.A., Varadarajan, P.R. and Zeithaml, C.P. (1988), “The contingency approach: its foundations and relevance to theory building and research in marketing", The European Journal of Marketing, Vol. 22, Issue 7, pp.37 - 64.

Zuurbier, P.J.P. (1999), "Supply chain management in the fresh produce industry: a mile to go?", Journal of Food Distribution Research, Vol. 30, Issue 1, pp. 20-30. 
Table 1: Factor analysis (principal-factor method) - rotated factor loadings

\begin{tabular}{|c|c|c|c|c|c|c|c|c|}
\hline Factor: & $c_{1}$ & $c_{2}$ & $c_{3}$ & $c_{4}$ & $c_{5}$ & $c_{6}$ & $c_{7}$ & Uniqueness \\
\hline Share information openly & & & 0.887 & & & & & 0.017 \\
\hline Keep each other informed about events or changes that might affect the other party & & & 0.883 & & & & & 0.013 \\
\hline Inform each other in advance of changing needs & & & 0.889 & & & & & 0.012 \\
\hline Willingly share even confidential information that might be useful to both parties & & & 0.861 & & & & & 0.050 \\
\hline Share information with each other on a regular basis & & & 0.828 & & & & & 0.088 \\
\hline Only provide information with each other according to pre-specified agreements [R] & & & 0.855 & & & & & 0.119 \\
\hline Support each other's objectives & 0.894 & & & & & & & 0.004 \\
\hline Share the same goals in the relationship & 0.897 & & & & & & & 0.002 \\
\hline Have agreement on the importance of improvements that benefit us & 0.889 & & & & & & & 0.014 \\
\hline Have compatible business goals & 0.898 & & & & & & & 0.006 \\
\hline Jointly develop plans to achieve our goals & 0.885 & & & & & & & 0.023 \\
\hline Have aligned business goals & 0.898 & & & & & & & 0.003 \\
\hline Have different goals $[R]$ & 0.896 & & & & & & & 0.013 \\
\hline Tend to jointly plan about production (e.g. product assortment) & & & & & & 0.632 & & 0.258 \\
\hline Try to synchronise our decisions in planning of demand and supply (e.g. volume of peaches) & & & & & & 0.714 & & 0.042 \\
\hline Tend to jointly work out solutions & & & & & & 0.726 & & 0.010 \\
\hline Try to work together in planning of all aspects of the delivery of the produce & & & & & & 0.731 & & 0.013 \\
\hline Try to coordinate decisions to solve any packaging issues & & & & & & 0.682 & & 0.163 \\
\hline Tend to work together to fulfil customers' orders & & & & & & 0.531 & & 0.328 \\
\hline Make efforts to cooperate when planning operations & & & & & & 0.711 & & 0.034 \\
\hline Share each other's performance & & & & & 0.648 & & & 0.173 \\
\hline Share costs incurred in order changes & & & & & 0.727 & & & 0.016 \\
\hline Share benefits (e.g. better return from sales) & & & & & 0.714 & & & 0.017 \\
\hline Share any risk that can occur in unforeseen situations & & & & & 0.719 & & & 0.011 \\
\hline Share costs on practices that minimize damaging routines & & & & & 0.723 & & & 0.012 \\
\hline Align benefits with cost and/or risk & & & & & 0.714 & & & 0.014 \\
\hline Volunteer to share any additional cost or benefits & & & & & 0.686 & & & 0.043 \\
\hline
\end{tabular}


Share resources (e.g. personnel, facilities and equipment)

Have mutual resources contribution in this relationship

Often combine resources to aid business activities

Both contribute resources to deal with any business problems

Both allocate resources to improve business processes

Have open two-way communication

Try to keep informal communication between us

Have frequent contacts on weekly basis

Have many different channels to communicate (e.g. face-to-face, text messages, e-mails)

Give each other opportunities to express essential information

Find it hard to inform each other about any business activities [R]

By working together we expand our business 'know-how'

Our working relationship provides opportunities to enhance our understanding of how to do better business

Our understanding of the business processes has improved by working together

Jointly generate better ideas to cope with any market uncertainties

By attending training seminars together, we develop better business methods

\section{Do not access any new knowledge by working together $[R]$}

\section{Proportion}

\section{Notes:}


Table 2: Types of collaboration and level of PHFL - OLS and Quantile regression

\begin{tabular}{|c|c|c|c|c|c|c|c|c|}
\hline \multirow{2}{*}{$\begin{array}{ll} & \text { Specification: } \\
\text { Variable }\end{array}$} & \multicolumn{2}{|c|}{ OLS } & \multicolumn{2}{|c|}{$q(25)$} & \multicolumn{2}{|c|}{$q(50)$} & \multicolumn{2}{|c|}{$\mathrm{q}(75)$} \\
\hline & Coef. & $\mathrm{P}>|\mathrm{t}|$ & Coef. & $\mathrm{P}>|\mathrm{t}|$ & Coef. & $\mathrm{P}>|\mathrm{t}|$ & Coef. & $\mathrm{P}>|\mathrm{t}|$ \\
\hline Goal congruence & -3.591 & 0.000 & -3.069 & 0.000 & -4.300 & 0.000 & -4.062 & 0.000 \\
\hline Communication & -2.118 & 0.000 & -1.448 & 0.022 & -2.178 & 0.000 & -2.290 & 0.000 \\
\hline Information sharing & -3.271 & 0.000 & -2.940 & 0.000 & -3.418 & 0.000 & -3.221 & 0.000 \\
\hline Resource sharing & -3.612 & 0.000 & -3.196 & 0.000 & -3.303 & 0.000 & -3.468 & 0.000 \\
\hline Incentive alignment & -3.106 & 0.000 & -3.161 & 0.000 & -3.183 & 0.000 & -2.739 & 0.001 \\
\hline Decision synchronisation & -1.894 & 0.000 & -1.539 & 0.000 & -2.141 & 0.000 & -2.322 & 0.010 \\
\hline Joint knowledge creation & -2.075 & 0.000 & -1.677 & 0.000 & -1.999 & 0.000 & -2.219 & 0.000 \\
\hline Farming experience (in years) & -0.059 & 0.232 & -0.027 & 0.604 & -0.063 & 0.208 & -0.132 & 0.083 \\
\hline \multicolumn{9}{|l|}{ Types of peaches (Mixed) } \\
\hline Peaches for processing only & -5.243 & 0.044 & -3.927 & 0.085 & -2.653 & 0.405 & -6.054 & 0.121 \\
\hline Table peaches only & -2.727 & 0.001 & -3.197 & 0.001 & -2.833 & 0.052 & -2.592 & 0.134 \\
\hline \multicolumn{9}{|l|}{ Age $(<31)$} \\
\hline $31-40$ & 1.483 & 0.186 & 1.858 & 0.134 & 2.430 & 0.070 & 2.149 & 0.153 \\
\hline $41-50$ & 2.478 & 0.078 & 2.475 & 0.165 & 3.114 & 0.046 & 3.382 & 0.081 \\
\hline$>50$ & 2.761 & 0.118 & 3.244 & 0.180 & 2.215 & 0.322 & 3.482 & 0.258 \\
\hline \multicolumn{9}{|c|}{ Education (low-level/no qualification) } \\
\hline High-level qualification & -2.243 & 0.075 & -0.862 & 0.546 & -1.483 & 0.335 & -1.563 & 0.346 \\
\hline Farm size (in acres) & 0.144 & 0.000 & 0.095 & 0.021 & 0.136 & 0.000 & 0.195 & 0.000 \\
\hline Farm size $^{2}$ & -0.000 & 0.000 & -0.000 & 0.125 & -0.000 & 0.001 & -0.001 & 0.001 \\
\hline \multicolumn{9}{|c|}{ Geographical location (Central Macedonia) } \\
\hline Thessaly & 1.535 & 0.294 & 2.023 & 0.316 & 1.750 & 0.335 & 2.271 & 0.526 \\
\hline Western Macedonia & -3.897 & 0.005 & -2.947 & 0.039 & -3.727 & 0.070 & -8.161 & 0.000 \\
\hline Constant & 8.936 & 0.000 & 6.660 & 0.000 & 8.524 & 0.000 & 11.254 & 0.000 \\
\hline $\mathrm{R}^{2} /$ Pseudo $\mathrm{R}^{2}$ & \multicolumn{2}{|c|}{0.730} & \multicolumn{2}{|c|}{0.536} & \multicolumn{2}{|c|}{0.556} & \multicolumn{2}{|c|}{0.492} \\
\hline Observations & \multicolumn{2}{|c|}{215} & & & \multicolumn{2}{|r|}{215} & & \\
\hline
\end{tabular}


Table 3: Types of collaboration and proportion of low-quality peaches - Quantile regression

\begin{tabular}{|c|c|c|c|c|c|c|}
\hline \multirow{2}{*}{$\begin{array}{ll} & \text { Quantile: } \\
\text { Variable }\end{array}$} & \multicolumn{2}{|c|}{$\mathrm{q}(25)$} & \multicolumn{2}{|c|}{$q(50)$} & \multicolumn{2}{|c|}{$\mathrm{q}(75)$} \\
\hline & Coef. & $P>|t|$ & Coef. & $\mathrm{P}>|\mathrm{t}|$ & Coef. & $\mathrm{P}>|\mathrm{t}|$ \\
\hline Goal congruence & -1.225 & 0.398 & -0.742 & 0.000 & -0.662 & 0.000 \\
\hline Communication & -0.374 & 0.488 & -0.288 & 0.003 & -0.364 & 0.000 \\
\hline Information sharing & -0.643 & 0.468 & -0.419 & 0.000 & -0.511 & 0.000 \\
\hline Resource sharing & -1.010 & 0.489 & -0.579 & 0.000 & -0.455 & 0.000 \\
\hline Incentive alignment & -1.156 & 0.451 & -0.544 & 0.000 & -0.459 & 0.000 \\
\hline Decision synchronisation & -0.712 & 0.485 & -0.305 & 0.003 & -0.269 & 0.002 \\
\hline Joint knowledge creation & -0.862 & 0.385 & -0.420 & 0.000 & -0.361 & 0.000 \\
\hline Farming experience (in years) & -0.031 & 0.634 & -0.017 & 0.221 & -0.032 & 0.010 \\
\hline \multicolumn{7}{|l|}{ Types of peaches (Mixed) } \\
\hline Peaches for processing only & -19.941 & 0.029 & -22.576 & 0.025 & -1.255 & 0.905 \\
\hline Table peaches only & -0.606 & 0.581 & -0.468 & 0.033 & -0.426 & 0.070 \\
\hline \multicolumn{7}{|l|}{ Age $(<31)$} \\
\hline $31-40$ & 0.373 & 0.797 & 0.103 & 0.744 & 0.401 & 0.076 \\
\hline $41-50$ & 0.961 & 0.569 & 0.502 & 0.165 & 0.850 & 0.022 \\
\hline$>50$ & 1.274 & 0.595 & 0.601 & 0.149 & 0.645 & 0.042 \\
\hline \multicolumn{7}{|c|}{ Education (low-level/no qualification) } \\
\hline High-level qualification & 0.763 & 0.832 & 0.163 & 0.699 & -0.313 & 0.301 \\
\hline Farm size (in acres) & -0.022 & 0.595 & -0.019 & 0.039 & -0.031 & 0.000 \\
\hline Farm size ${ }^{2}$ & 0.000 & 0.790 & 0.000 & 0.436 & 0.000 & 0.013 \\
\hline \multicolumn{7}{|c|}{ Geographical location (Central Macedonia) } \\
\hline Thessaly & 0.269 & 0.959 & 0.103 & 0.831 & -0.503 & 0.307 \\
\hline Western Macedonia & -18.394 & 0.010 & -1.390 & 0.713 & -1.635 & 0.000 \\
\hline Constant & -0.846 & 0.795 & 0.285 & 0.509 & 1.536 & 0.000 \\
\hline Observations & \multicolumn{6}{|c|}{215} \\
\hline
\end{tabular}


Figure 1: Distribution of the dependent variables.

a) PHFL $\left(\overline{l_{L}}\right)$ in tonnes
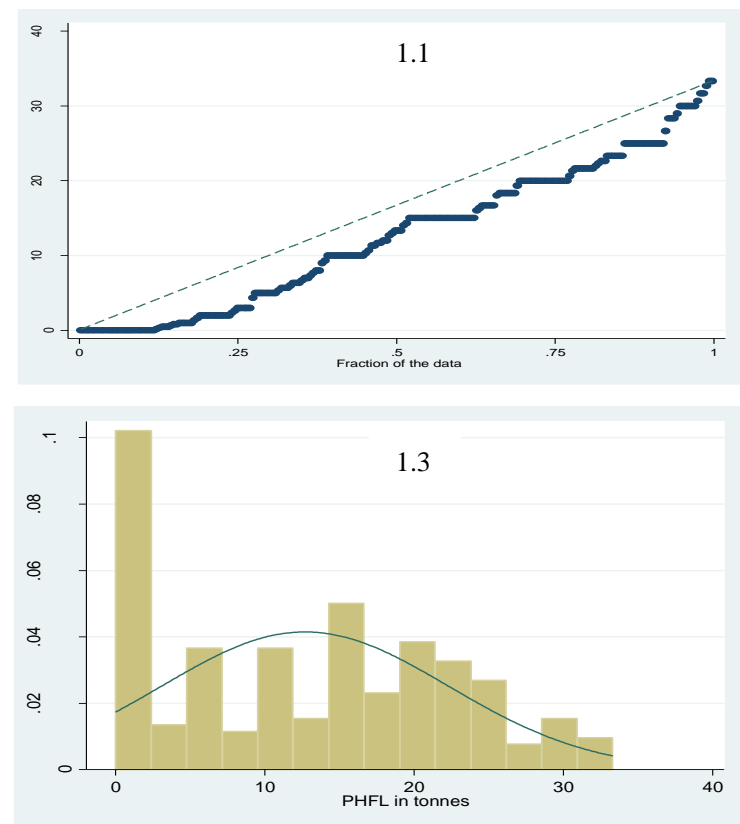

b) Proportion of low-quality peaches $\left(\bar{f}_{l}\right)$
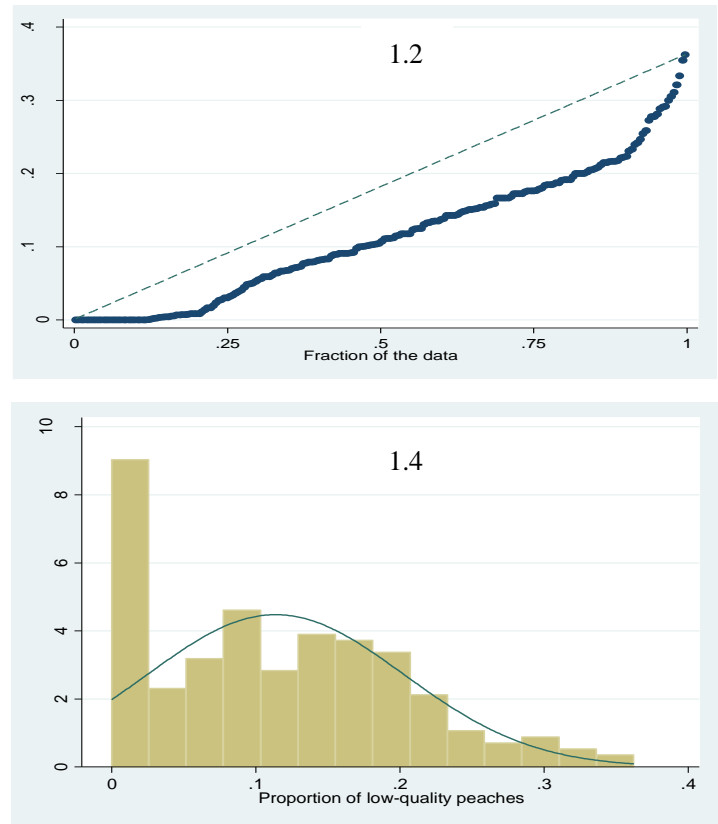

Notes:

1.1-1.2 Quantile plots for PHFL in tones and Ratio of low-quality peaches to peach production. 1.3-1.4 Histograms for PHFL in tones and Ratio of low-quality peaches to peach production. 
Figure 2: Conceptual model.

Collaborative relationships

- Goal congruence (-)

- Communication (-)

- Information sharing (-)

- Resource sharing (-)

- Incentive alignment (-)

- Decision synchronization $(-)$

- Joint knowledge creation $(-)$

\begin{tabular}{|c|c|}
\hline H1a-b & $\begin{array}{l}\text { PHFL } \\
\text { - Level of the PHFL } \\
\text { - Ratio of low-quality peaches to } \\
\text { peach production }\end{array}$ \\
\hline & $\begin{array}{l}\text { Controls } \\
\text { - Farming experience } \\
\text { - Types of peaches } \\
\text { - Age } \\
\text { - Education } \\
\text { - Farm size } \\
\text { - Geographical location }\end{array}$ \\
\hline
\end{tabular}


Figure 3: Variation in the collaboration coefficient over the conditional quantiles.
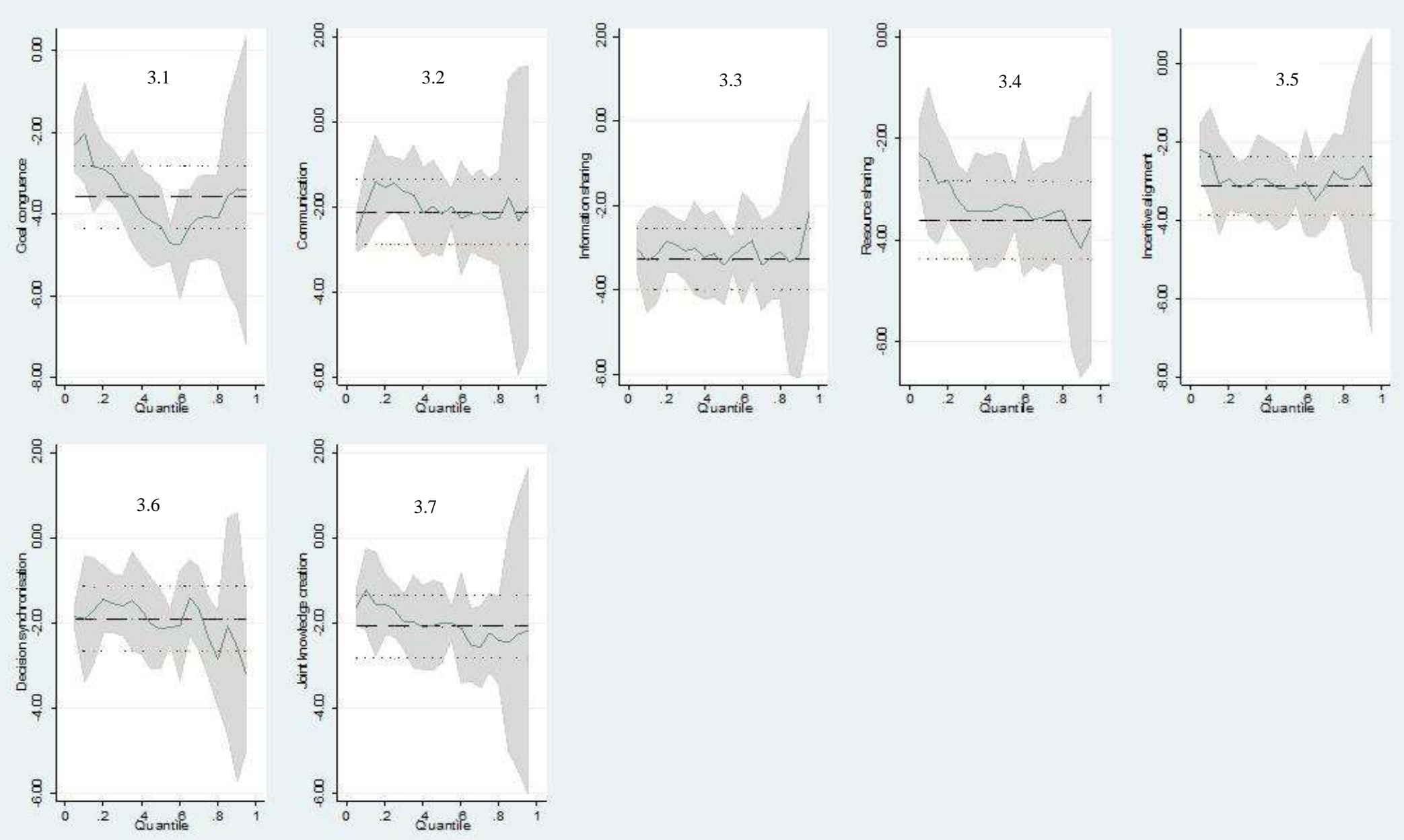

Notes:

3.1 Variation in the "goal congruence" coefficient over the conditional quantiles. 
3.2 Variation in the "communication" coefficient over the conditional quantiles.

3.3 Variation in the "information sharing" coefficient over the conditional quantiles.

3.4 Variation in the "resource sharing" coefficient over the conditional quantiles.

3.5 Variation in the "incentive alignment" coefficient over the conditional quantiles.

3.6 Variation in the "decision synchronisation" coefficient over the conditional quantiles.

3.7 Variation in the "joint knowledge creation" coefficient over the conditional quantiles. 
Figure 4: Estimates and the $95 \%$ confidence bands for the regression coefficients of collaboration for a dense set of quantiles
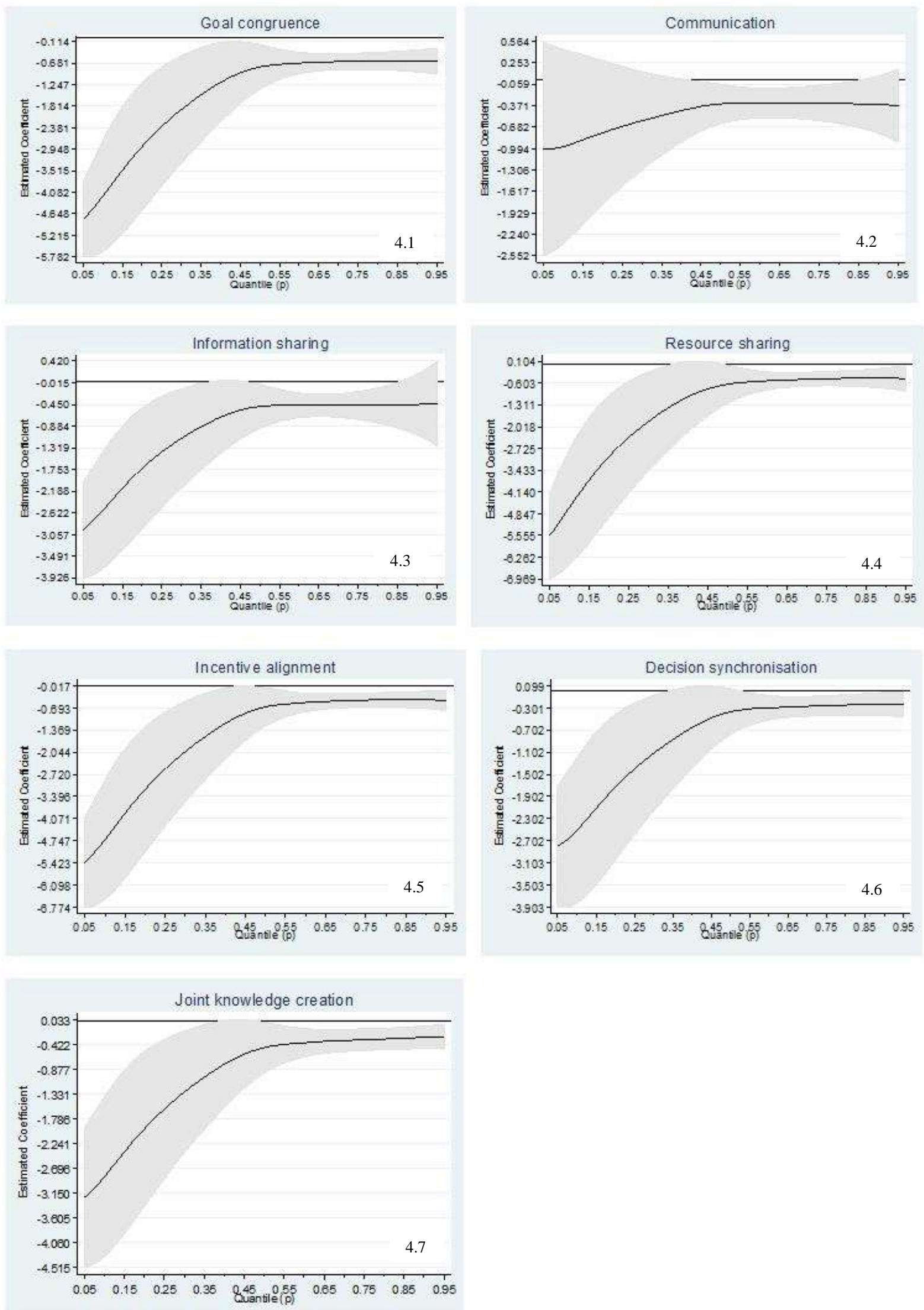


\section{Notes:}

4.1 Estimates and the $95 \%$ confidence bands for the regression coefficients of "goal congruence".

4.2 Estimates and the $95 \%$ confidence bands for the regression coefficients of "communication".

4.3 Estimates and the $95 \%$ confidence bands for the regression coefficients of "information sharing".

4.4 Estimates and the $95 \%$ confidence bands for the regression coefficients of "resource sharing".

4.5 Estimates and the $95 \%$ confidence bands for the regression coefficients of "incentive alignment".

4.6 Estimates and the $95 \%$ confidence bands for the regression coefficients of "decision synchronisation".

4.7 Estimates and the $95 \%$ confidence bands for the regression coefficients of "joint knowledge creation". 


\section{Appendix 1}

\section{A1.1. Modelling PHFL $\left(\overline{l_{l}}\right)$ in tonnes}

To estimate the $q$ th $(0<q<1)$ regression quantile the check loss function $\rho_{q}$ is used:

$\rho_{q}\left(u_{q, i}\right)= \begin{cases}q u_{q, i} & \text { if } u_{q, i} \geq 0 \\ (q-1) u_{q, i} & \text { if } u_{q, i}<0\end{cases}$

Our model has the following linear form:

$\bar{l}_{i}=x_{i}^{\prime} \beta_{q}+u_{q, i}$, with $Q_{q\left(\bar{l}_{i} \mid x_{i}\right)=x_{i}^{\prime} \beta_{q}}$

where $x$ is the vector of regressors, $\beta$ is the vector of coefficients to be estimated and $u$ is a vector of residuals. Using linear programming methods $\beta$ can be estimated as:

$\widehat{\beta_{q}}=\arg \min _{\beta}\left(\frac{1}{n}\right)\left\{\sum_{i: l_{i} \geq x_{i}^{\prime} \beta} q\left|\bar{l}_{i}-x_{i}^{\prime}\right|+\sum_{i: l_{i}<x_{i}^{\prime} \beta}(1-q)\left|y_{i}-x_{i}^{\prime} \beta\right|\right\}=$ $\arg \min _{\beta}\left(\frac{1}{n}\right) \sum_{i=1}^{n} \rho_{q} u_{q, i}$

\section{A1.2. Modelling the proportion of low-quality peaches $\left(\bar{f}_{l}\right)$}

Following Bottai et al. (2010), for any given quantile $(q)$ we assume that there exists a fixed set of parameters $\left(\beta_{q}\right)$ and a known non-increasing function $h$ from the interval $\left(\bar{f}_{l_{\text {min }}}, \bar{f}_{l_{\text {max }}}\right)$ to the real line such that:

$$
h\left(Q_{f}\left(q_{i}\right)\right)=x_{i}^{\prime} \beta_{q}
$$

-where $Q_{f}(q)$ is the conditional $q$ th quantile of $\bar{f}_{l}$ given our set of covariates - and opt for logistic transformation:

$h\left(\bar{f}_{l}\right)=\log \left(\bar{f}_{l_{l}}-\bar{f}_{l_{\text {min }}}\right)=\operatorname{logit}\left(\bar{f}_{l_{i}}\right)$

Equation (5) implies that:

$$
Q_{f}(q)=\frac{\exp \left(x_{i}^{\prime} \beta_{q}\right) \bar{f}_{l_{\text {max }}}+\bar{f}_{l_{\text {min }}}}{\exp \left(x_{i}^{\prime} \beta_{q}\right)+1}
$$


The coefficients are obtained via quantile regression by regressing the transformed outcome of $h\left(\overline{f_{l}}\right)$ on $x_{i}$ and inferences about $Q_{f}(q)$ can be made via the inverse transom in equation (A6) since:

$Q_{h\left(\bar{f}_{l}\right)}(q)=Q_{\operatorname{logit}\left(\bar{f}_{l}\right)}(q)=\beta_{q, 0}+\sum_{i=1}^{m} x_{i} \beta_{q, i}$ 